OPEN ACCESS

Edited by:

Mohammed Rahmatullah, University of Development Alternative,

Bangladesh

Reviewed by:

Radu Adrian Crisan Dabija, Grigore T. Popa University of Medicine and Pharmacy, Romania David De Jong, University of São Paulo Ribeirão Preto,

Brazil

*Correspondence: Serawit Deyno dserawit@std.must.ac.ug

Specialty section: This article was submitted to Ethnopharmacology,

a section of the journal Frontiers in Pharmacology

Received: 19 March 2021 Accepted: 07 December 2021 Published: 24 December 2021

Citation:

Beressa TB, Deyno S, Mtewa AG, Aidah N, Tuyiringire N, Lukubye B, Weisheit A, Tolo CU and Ogwang PE (2021) Potential Benefits of Antiviral

African Medicinal Plants in the Management of Viral Infections: Systematic Review.

Front. Pharmacol. 12:682794. doi: 10.3389/fphar.2021.682794

\section{Potential Benefits of Antiviral African Medicinal Plants in the Management of Viral Infections: Systematic Review}

\author{
Tamirat Bekele Beressa ${ }^{1}$, Serawit Deyno ${ }^{2,3 *}$, Andrew G. Mtewa ${ }^{4}$, Namuli Aidah $^{2}$, \\ Naasson Tuyiringire ${ }^{2,5}$, Ben Lukubye ${ }^{6}$, Anke Weisheit ${ }^{2}$, Casim Umba Tolo $^{2}$ and \\ Patrick Engeu Ogwang ${ }^{2}$
}

\begin{abstract}
${ }^{1}$ Department of Pharmacy, College of Medicine and Health Sciences, Ambo University, Ambo, Ethiopia, ${ }^{2}$ Pharm-Biotechnology and Traditional Medicine Center of Excellence, Mbarara University of Science and Technology, Mbarara, Uganda, ${ }^{3}$ School of Pharmacy, Faculty of Medicine, Hawassa University, Hawassa, Ethiopia, ${ }^{4}$ Chemistry Section, Department of Applied Studies, Institute of Technology, Malawi University of Science and Technology, Limbe, Malawi, ${ }^{5}$ School of Nursing and Midwifery, College of Medicine and Health Sciences, University of Rwanda, Butare, Rwanda, ${ }^{6}$ Department of Biology, Faculty of Science, Mbarara University of Science and Technology, Mbarara, Uganda
\end{abstract}

Background: Viruses cause various human diseases, some of which become pandemic outbreaks. This study synthesized evidence on antiviral medicinal plants in Africa which could potentially be further studied for viral infections including Coronavirus disease 2019 (COVID-19) treatment.

Methods: PUBMED, CINAHIL, Scopus, Google Scholar, and Google databases were searched through keywords; antiviral, plant, herb, and Africa were combined using "AND" and "OR". In-vitro studies, in-vivo studies, or clinical trials on botanical medicine used for the treatment of viruses in Africa were included.

Results: Thirty-six studies were included in the evidence synthesis. Three hundred and twentyeight plants were screened for antiviral activities of which 127 showed noteworthy activities against 25 viral species. These, were Poliovirus (42 plants), HSV (34 plants), Coxsackievirus (16 plants), Rhinovirus (14plants), Influenza (12 plants), Astrovirus (11 plants), SARS-CoV-2 (10 plants), HIV (10 plants), Echovirus (8 plants), Parvovirus (6 plants), Semiliki forest virus (5 plants), Measles virus (5 plants), Hepatitis virus (3 plants), Canine distemper virus (3 plants), Zika virus (2 plants), Vesicular stomatitis virus T2 (2 plants). Feline herpesvirus (FHV-1), Enterovirus, Dengue virus, Ebola virus, Chikungunya virus, Yellow fever virus, Respiratory syncytial virus, Rift Valley fever virus, Human cytomegalovirus each showed sensitivities to one plant.

Conclusion: The current study provided a list of African medicinal plants which demonstrated antiviral activities and could potentially be candidates for COVID-19 treatment. However, all studies were preliminary and in vitro screening. Further in vivo studies are required for plant-based management of viral diseases.

Keywords: SARS-CoV-2 (2019-nCoV), medicinal plants, viral infections, Africa, herbal mecidine

\footnotetext{
Abbreviations: $\mathrm{CC}_{50}, 50 \%$ cytotoxic concentration; COVID-19, coronavirus diseases 2019; $\mathrm{EC}_{50}$, half maximal effective concentration; HIV, human immune deficiency virus; HSV, herpes simplex virus; MERS-CoV, middle east respiratory syndrome coronavirus; PRISMA, preferred reporting items for systematic reviews and meta-analysis; SARS-CoV, severe acute respiratory syndrome coronavirus; SI, selective index; CHM, chinese herbal medicine.
} 


\section{BACKGROUND}

Viruses cause various human diseases of which several such as Ebola, HIV/AIDS, and Hepatitis B are hard to treat. Many pandemic outbreaks in world history were caused by a viral infection. The Spanish flu pandemic of 1918, the deadliest in history, infected an estimated 500 million people worldwide; which is about one-third of the planet's population, and killed an estimated 20 million to 50 million people (1). In recent years, pandemics have arisen and have also been contained using various approaches. For example, Ebola virus outbreak between 2013 and 2016 with 11323 deaths (Trilla et al., 2008), Coronavirus (Severe Acute Respiratory Syndrome (SARS) with deaths of 229 (World Health Organization, 2003), Middle East respiratory syndrome (MERS) as of May 31, 2015, which had 483 (40\%) mortality (Zumla et al., 2015) are some of the recorded global pandemics. Since December 2019 the world is suffering from Coronavirus disease 2019 (COVID-19) with more than 197 million people infected and more than 4, 219, 861 deaths as of August 4, 2021 (World Health Organization, 2020).

The use of natural medicinal agents dates back to human prehistory where plants formed the basis of traditional medicine (TM) systems. Traditional medicine refers to health practices, approaches, knowledge, and beliefs incorporating plant, animal, and mineral-based medicines, spiritual therapies, manual techniques, and exercises which are applied singularly or in combination to treat or to diagnose and prevent illnesses or maintain well-being (World Health Assembly, 2003). Traditional medicine has a high influence on the African health system with an estimated $80 \%$ of the population depending on TM practice for primary health care purposes (World Health Organization, 2005). The availability and affordability of the TM aligned with inherited knowledge of the practice in local communities might have contributed to their wide use (Fennell et al., 2004).

Several herbal medicines have been used to treat viral infections traditionally for a long time. Some studies have reported the inhibitory effect of medicinal plant extracts against several viruses. Some of these studies were conducted on HIV, herpes simplex virus, hepatitis B virus, and poliovirus. For example, ethnobotanical studies in Africa described the treatment of viral hepatitis with traditional medicine in Africa (Vlietinck et al., 1995; Sindambiwe et al., 1999; Cos et al., 2002a; Amenu, 2007; Abera, 2014; Traore et al., 2018). Furthermore, plants have been reported to have antiviral potential against conventional medicine-resistant strains of viruses (Serkedjieva, 2003). Nine traditional Chinese botanicals were optimized to treat the symptoms of SARS during its outbreak (Zhang et al., 2004). In another study, small molecules from natural compounds have been screened and confirmed to inhibit important proteins in SARS or MERS coronavirus (Zhang et al., 2020). Despite having lots of endemic knowledge and practice on African herbal medicine, there is a paucity of scientific evidence on their efficacy and safety. This study aimed to summarize the evidence on antiviral medicinal plants in Africa which could potentially be further studied for COVID19 treatment.

\section{METHODS}

\section{Study Design}

This review was conducted using database searches and followed statements for Reporting Systematic Reviews and Meta-Analyses (Liberati et al., 2009).

\section{Search Strategy}

Data were collected from MEDLINE/PUBMED, CINAHIL, Google Scholar, and Scopus databases. No language limitations were applied to reduce selection bias and Google was used to translate articles published in other languages than English. The search strategy used the following terms with appropriate Boolean operators; ("virus diseases" OR ("virus" AND “diseases") OR "virus diseases" OR ("viral” AND "infection") OR "viral infection”) OR ("poliovirus" OR "poliovirus” OR HSV OR ("simplexvirus" OR "simplexvirus" OR ("herpes" AND "simplex" AND "virus") OR "herpes simplex virus") OR ("enterovirus" OR "enterovirus" OR "coxsackievirus" OR (“influenza, human" OR ("influenza" AND "human”) OR "human influenza" OR "influenza") OR (astro AND ("viruses" OR “viruses” OR “virus”)) OR (“parvovirus” OR "parvovirus”) OR ("rhinovirus" OR "rhinovirus") OR ("enterovirus b, human" OR "human enterovirus b” OR “echovirus") OR ("hiv"OR "hiv") OR ("hiv"OR "hiv" OR ("human" AND "immunodeficiency" AND "virus") OR "human immunodeficiency virus") OR (semiliki AND ("forests"OR "forests" OR "forest") AND (“viruses"OR “viruses” OR "virus”)) OR (“measles virus"OR ("measles" AND "virus") OR "measles virus") OR ("hepatitis viruses"OR ("hepatitis" AND "viruses") OR "hepatitis viruses" OR ("hepatitis" AND "virus") OR "hepatitis virus") OR ("zika virus"OR ("zika” AND “virus") OR “zika virus”) OR (("vesicular stomatitis indiana virus"OR ("vesicular" AND "stomatitis" AND "indiana" AND "virus") OR "vesicular stomatitis indiana virus" OR ("vesicular" AND "stomatitis" AND “virus") OR "vesicular stomatitis virus") AND T2) OR (“coronavirus disease 2019” OR "COVID-2019") AND "herbal medicine" OR "traditional medicine" OR "oriental medicine" OR "Chinese medicine" OR "African medicine" OR "herbal formula" OR herb AND") AND (" AND ("africa"OR "africa") AND "OR" AND (("african continental ancestry group"OR ("african" AND "continental" AND "ancestry" AND "group") OR "african continental ancestry group” OR “african”) AND countries).

\section{Study Selection}

We included original research articles and unpublished dissertations from their inception to 2020. The unpublished dissertations were obtained from university website (http:// etd.aau.edu.et, http://erepository.uonbi.ac.ke). EndNote reference manager was used to remove the duplications of references before screening. Either in vitro studies or in vivo studies or clinical trials of herbal medicine on African medicinal plants were included. Studies were eligible for inclusion if they were conducted to determine antiviral activities using available scientific methods and conducted on medicinal plants in Africa. Studies conducted on 


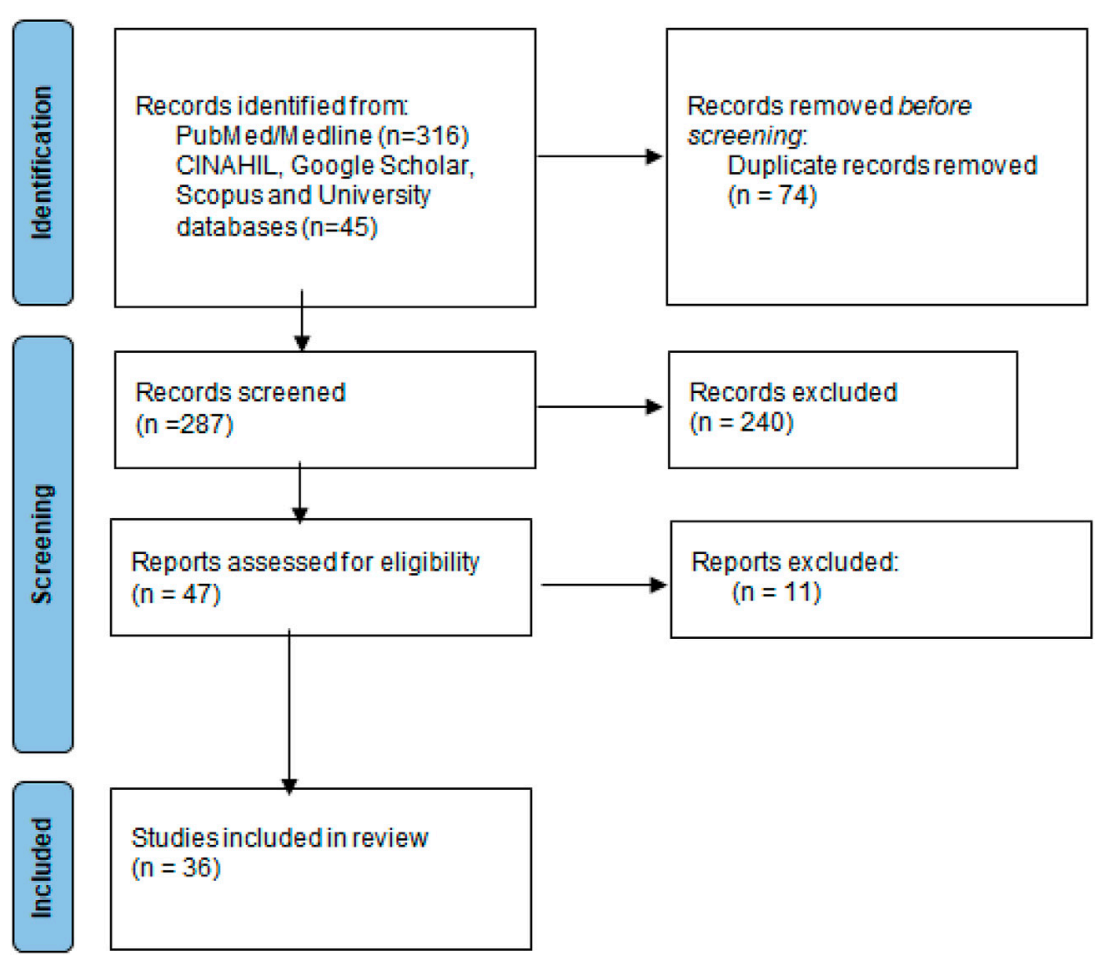

FIGURE 1 | Flow diagram of included studies. Legend: The PRIMSA diagram details our search and selection process applied during the review.

medicinal plants outside of Africa were excluded from the study. Review articles and ethnobotanical studies were also excluded. Eligibility assessment was conducted by TB and SD independently and disagreement between authors was resolved by discussion.

\section{RESULTS}

In this study 316 publications were retrieved of which 36 (Ferrea et al., 1993; Beuscher et al., 1994; Vlietinck et al., 1995; Nakano et al., 1997; Kitamura et al., 1998; Hussein et al., 1999; Kudi and Myint, 1999; Sindambiwe et al., 1999; Anani et al., 2000; Yoosook et al., 2000; Cos et al., 2002b; Chiang et al., 2003; Wang et al., 2004; Bessong et al., 2005; Gebre-Mariam et al., 2006; Tolo et al., 2006; Kambizi et al., 2007; Maregesi et al., 2008; Duraipandiyan and Ignacimuthu, 2009; Gyuris et al., 2009; Ojo et al., 2009; Selvarani, 2009; Sunday et al., 2010; Astani et al., 2011; Nwodo et al., 2011; Sultana, 2011; Ndhlala et al., 2013; Ogbole et al., 2013; Kwena, 2014; David et al., 2017; Clain et al., 2018; Mehrbod et al., 2018; Nasr-Eldin et al., 2018; Ogbole et al., 2018; Cambaza, 2020; Gyebi et al., 2021) were included in the qualitative synthesis, Figure 1.

Three hundred and twenty-eight plants were screened for antiviral activities of which 127 tested showed activities against 25 viral species; Among these were Poliovirus (42 plants), HSV (34 plants), Coxsackievirus (16 plants), Rhinovirus (14plants), Influenza (12 plants), Astrovirus (11 plants), SARS-CoV-2 (10 plants), HIV (10 plants), Echovirus
(8 plants), Parvovirus (6 plants, Semiliki forest virus (5 plants), Measles virus (5 plants), Hepatitis virus (3 plants), Canine distemper virus (3 plants), Zika virus (2 plants), Vesicular stomatitis virus T2 (2 plants). Feline herpes virus (FHV-1), Enterovirus, Dengue virus, Ebola virus, Chikungunya virus, Yellow fever virus, Respiratory syncytial virus, Rift Valley fever virus, Human cytomegalovirus each showed sensitivities to one plant (Tables 1-4). Isolated compounds were also identified and their activities outlined, namely alkaloids (combretine and betonicine) from Combretum micrantum (Ferrea et al., 1993), Aloin from Aloe ferox (Kambizi et al., 2007), a polysaccharide from Aspalathus. Linearis (Nakano et al., 1997), Asiaticoside from Centella asiatica (Yoosook et al., 2000), Catechin from S. frutescens (Bessong et al., 2005).

\section{DISCUSSION}

This study summarized the antiviral activities of African medicinal plants. Forty two African medicinal plants showed noteworthy activities against poliovirus and twenty four against HSV.

\section{Medicinal Plants Used for Severe Acute Respiratory Syndrome}

Recently, 10 African medicinal plants from Morocco showed noteworthy activities against SARS-CoV-2 (58). However, there is 
TABLE 1 | Antiviral activity of African medicinal plants against HIV virus.

\begin{tabular}{|c|c|c|c|c|}
\hline Species, Family & $\begin{array}{l}\text { Parts } \\
\text { used }\end{array}$ & $\begin{array}{l}\text { Extracting } \\
\text { solvent }\end{array}$ & Activity & References \\
\hline $\begin{array}{l}\text { Aspalathus linearis (Burm.f.) } \\
\text { R.Dahlgren (Fabaceae) }\end{array}$ & $L$ & Alkaline water & Active against HIV with $\left(\mathrm{EC}_{50}=38.9 \mu \mathrm{g} / \mathrm{ml}\right)$ & $\begin{array}{l}\text { Nakano et al. } \\
\text { (1997) }\end{array}$ \\
\hline $\begin{array}{l}\text { Croton megalobotrys Müll.Arg. } \\
\text { (Euphorbiaceae) }\end{array}$ & $\mathrm{R}$ & Methanol & Activates latent $\mathrm{HIV}-1$ provirus in J-lat cells at $0.5 \mu \mathrm{g} / \mathrm{ml}=1.3 \pm 0.2 \%$ & Tietjen et al. (2016) \\
\hline Euphorbia hirta L. (Euphorbiaceae) & $\mathrm{AP}$ & Methanol & Active againist HIV-1, with $\left(\mathrm{IC}_{50}=560.5 \mu \mathrm{g} / \mathrm{ml}\right)$ & Gyuris et al. (2009) \\
\hline $\begin{array}{l}\text { Hypericum revolutum Vahl } \\
\text { (Hypericaceae) }\end{array}$ & $\mathrm{L}$ & Ethanol & Active against $\mathrm{HIV}-1$ with $\mathrm{EC}_{50}>131.13 \mu \mathrm{g} / \mathrm{ml}$ and $\mathrm{CC}_{50}>131.13 \mu \mathrm{g} / \mathrm{ml}$ & Cos et al. (2002b) \\
\hline $\begin{array}{l}\text { Microglossa pyrifolia (Lam.) Kuntze } \\
\text { (Asteraceae) }\end{array}$ & S & Ethanol & Active againist $\mathrm{HIV}-1$ with $\mathrm{EC}_{50}>140.1 \mu \mathrm{g} / \mathrm{ml}$, and $\left.\mathrm{CC}_{50}=140.1 \mu \mathrm{g} / \mathrm{ml}\right)$ & Cos et al. (2002b) \\
\hline $\begin{array}{l}\text { Sutherlandia frutescens (L.) R.Br. } \\
\text { (Fabaceae) }\end{array}$ & $\mathrm{L}$ & $\begin{array}{l}\text { Methanol } \\
\text { Methanol }\end{array}$ & $\begin{array}{l}\text { Active against HIV RNA-dependent DNA polymerase (RDDP) } I_{50}= \\
2000 \mu \mathrm{g} / \mathrm{ml} \text {, RNase } \mathrm{H} \mathrm{IC} \mathrm{C}_{50}>100 \mu \mathrm{g} / \mathrm{ml} \\
\text { Acts on HIV RNA-dependent DNA polymerase (RDDP) with } \mathrm{IC}_{50}=2000 \mu \mathrm{g} / \\
\mathrm{ml} \text {, and RNase } \mathrm{H} \mathrm{IC}_{50}>100 \mu \mathrm{g} / \mathrm{ml}\end{array}$ & $\begin{array}{l}\text { Bessong et al. } \\
\text { (2005) }\end{array}$ \\
\hline $\begin{array}{l}\text { Terminalia sericea Burch. ex DC. } \\
\text { (Rutaceae) }\end{array}$ & $\mathrm{L}$ & Methanol & Inhibits HIV-1 RDDPby (98\%); HIV-1, and RNase inhibition by $99.3 \%$ & $\begin{array}{l}\text { Bessong et al. } \\
\text { (2005) }\end{array}$ \\
\hline $\begin{array}{l}\text { Triumfetta rhomboidea Jacq. } \\
\text { (Malvaceae) }\end{array}$ & $\mathrm{L}$ & Ethanol & Active against $\mathrm{HIV}-1$ with $\mathrm{EC}_{50} \geq 0.03$, and $\left.\mathrm{CC}_{50}=0.03 \mu \mathrm{g} / \mathrm{ml}\right)$ & Cos et al. (2002a) \\
\hline Triumfetta rhomboidea (Tiliaceae) & $\mathrm{L}$ & Ethanol & Active against HIV-1 with $\mathrm{EC}_{50}>0.03$ and $\mathrm{CC}_{50}=0.03$ & Cos et al. (2002b) \\
\hline
\end{tabular}

AP, areal part; L, leaf; S, stem; $R$, root; $C_{5}$, The 50\% cytotoxic concentration; DNA, deoxyribonucleic acid; EC $C_{50}$, Half maximal effective concentration; HIV-1, human immunodeficiency virus type $1 ; I_{5}$, Half-maximal inhibitory concentration; $R N A$, ribonucleic acid.

TABLE 2 | Antiviral activity of African medicinal plants against Influenza virus.

\begin{tabular}{|c|c|c|c|c|}
\hline Species, Family & $\begin{array}{l}\text { Parts } \\
\text { used }\end{array}$ & Extracting solvent & Activity & References \\
\hline $\begin{array}{l}\text { Acokanthera schimperi (A.DC.) } \\
\text { Schweinf. (Apocynaceae) }\end{array}$ & $L$ & Hexane & $\begin{array}{l}\text { Inhibited parainfluenza virus production by } 50 \% \text { at } 1-10 \\
\text { dilution factor }\end{array}$ & Bagla et al. (2012) \\
\hline $\begin{array}{l}\text { Aspalathus linearis (Burm.f.) } \\
\text { R.Dahlgren (Fabaceae) }\end{array}$ & $L$ & Alkaline & Inhibited influenza A and Bvirus production by $50 \%$ & Rahmasaria et al. (2017) \\
\hline \multirow[t]{2}{*}{$\begin{array}{l}\text { Adansonta digitata } \\
\text { L.(Bombacaceae) }\end{array}$} & $L$ & Methanol & $\begin{array}{l}\text { Active againist Influenza } A\left(\mathrm{H}_{3} \mathrm{~N}_{2}\right) \text { virus human isolate } \\
\text { with MIC of } 0.72 \mu \mathrm{g} / \mathrm{ml}\end{array}$ & Selvarani, (2009) \\
\hline & $\begin{array}{l}\mathrm{L} \\
\mathrm{AP}\end{array}$ & DMSO & $\begin{array}{l}\text { Active againist Influenza } \mathrm{A}\left(\mathrm{H}_{3} \mathrm{~N}_{2}\right) \text { virus human isolate } \\
\text { with } \mathrm{MIC} \text { of } 0.12 \mu \mathrm{g} / \mathrm{ml} \text { annd } \mathrm{RSV} \text { with } \mathrm{MIC}= \\
16.2 \mu \mathrm{g} / \mathrm{ml}\end{array}$ & $\begin{array}{l}\text { Selvarani, (2009) } \\
\text { Clain et al. (2018) }\end{array}$ \\
\hline Carissa spinarum L. (Apocynaceae) & $\mathrm{L}$ & hexane & Inhibited parainfluenza virus by $25 \%$ at a 1 to 10 dilution & Bagla et al. (2012) \\
\hline $\begin{array}{l}\text { Rotheca myricoides var. discolor } \\
\text { (Klotzsch) Verdc. (Lamiaceae) }\end{array}$ & $L$ & Methanol & $\begin{array}{l}\text { Active against influenza } A \text { virus with } \mathrm{EC}_{50}=110.4 \mu \mathrm{g} / \mathrm{ml} \\
\text { and } \mathrm{CC}_{50}=221 \pm 34.9 \mu \mathrm{g} / \mathrm{ml} \text { ) }\end{array}$ & Mehrbod et al. (2018) \\
\hline $\begin{array}{l}\text { Helichrysum armenium DC. } \\
\text { (Asteraceae) }\end{array}$ & $L$ & Water and ethanol & Inhibited parainfluenza virus with MIC of $4 \mu \mathrm{g} / \mathrm{ml}$ & Bagla et al. (2012) \\
\hline $\begin{array}{l}\text { Helichrysum melanacme DC. } \\
\text { (Asteraceae) }\end{array}$ & $\mathrm{L}$ & Ethanol & $\begin{array}{l}\text { Inhibited influenza A virus production with } I_{50} \text { of } \\
10 \mu \mathrm{g} / \mathrm{ml}\end{array}$ & Rahmasaria et al. (2017) \\
\hline Pavetta ternifolia Hiern. Rubiaceae) & $\mathrm{L}$ & $\begin{array}{l}\text { Methanol, } 30 \text { and } 100 \% \\
\text { ethanol, Acetone }\end{array}$ & $\begin{array}{l}\text { Active against influenza A virus. For acetone extract with } \\
\mathrm{EC}_{50}=82.3 \mu \mathrm{g} / \mathrm{ml} \text { and } \mathrm{CC}_{50}=165 \pm 25.2 \mu \mathrm{g} / \mathrm{ml} \\
\text { For ethanol }(30 \%) \mathrm{CC}_{50}=77 \pm 24.8 \mu \mathrm{g} / \mathrm{ml}, \mathrm{EC}_{50}= \\
19.2 \mu \mathrm{g} / \mathrm{ml} \text { for ethanol (100\%) } \mathrm{CC}_{50}=7 \pm 5.8 \mu \mathrm{g} / \mathrm{ml} \\
\text { andEC }_{50}=3.4 \mu \mathrm{g} / \mathrm{ml} \mathrm{SI}=2 ; \text { For methanol } \mathrm{CC}_{50}=15 \pm \\
9.3 \mu \mathrm{g} / \mathrm{ml} \text { and } \mathrm{EC}_{50}=3.6 \mu \mathrm{g} / \mathrm{ml} \mathrm{Sl}=4\end{array}$ & Mehrbod et al. (2018) \\
\hline $\begin{array}{l}\text { Pelargonium sidoides DC. } \\
\text { (Geraniaceae) }\end{array}$ & $\begin{array}{l}\text { Not } \\
\text { specified }\end{array}$ & EPs 7630 & $\begin{array}{l}\text { Inhibited the replication of influenza } \mathrm{A} \mathrm{H}_{1} \mathrm{~N}_{1} \text { and } \mathrm{H}_{3} \mathrm{~N}_{2} \text { at } \\
\text { the concentration of } 100 \mu \mathrm{g} / \mathrm{ml}\end{array}$ & \\
\hline $\begin{array}{l}\text { Pterocarpus angolensis DC. } \\
\text { (Fabaceae) }\end{array}$ & $\begin{array}{l}\text { SB } \\
B, F, L\end{array}$ & Methanol & $\begin{array}{l}\text { Active against influenza } A \text { virus with } \mathrm{CC}_{50}=227 \pm 13.6 \\
\text { and } \mathrm{EC}_{50}=113.3\end{array}$ & Mehrbod et al. (2018) \\
\hline $\begin{array}{l}\text { Rapanea melanophloeos (L.) Mez } \\
\text { (Primulaceae) }\end{array}$ & L & $\begin{array}{l}\text { Water, methanol,ethanol, } \\
\text { aceton }\end{array}$ & Inhibited inlfuenza A virus with $\mathrm{EC}_{50}$ of $113 \mu \mathrm{g} / \mathrm{ml}$ & $\begin{array}{l}\text { Mehrbod et al. (2018), More } \\
\text { et al. (2021) }\end{array}$ \\
\hline Sterculia setigera Delile (Malvaceae) & $L$ & Hexane & Active against influenza $A$ virus $\left(E_{50}=4.7 \mu \mathrm{g} / \mathrm{ml}\right)$ & $\begin{array}{l}\text { Lu et al. (2005), Duraipandiyan } \\
\text { and Ignacimuthu, (2009) }\end{array}$ \\
\hline
\end{tabular}

$A P$, areal part; $B$, bark; $L$, leaf; $S B$, stem bark, $R$, root; $R B$, root bark; WP, whole plant; $F$, fruit; DMSO, dimethyl sulfoxide; $C C_{50}$, the $50 \%$ cytotoxic concentration; $E C_{50}$, half maximal effective concentration; MIC, minimum inhibitory concentration. 
TABLE 3 | Antiviral activity of African medicinal plants against Herpes simplex virus.

\begin{tabular}{|c|c|c|c|c|}
\hline Species, Family & $\begin{array}{l}\text { Parts } \\
\text { used }\end{array}$ & $\begin{array}{l}\text { Extracting } \\
\text { solvent }\end{array}$ & Activity & References \\
\hline Adansonta digitata L. (Bombacaceae) & $\mathrm{RB}, \mathrm{L}$ & Methanol & Active against HSV with MIC $65.5 \mu \mathrm{g} / \mathrm{ml}$ & Anani et al. (2000) \\
\hline Aloe ferox Mill. (Xanthorrhoeaceae) & L & Water & Active against $\mathrm{HSV}-1$ with $\mathrm{MIC}=63 \mu \mathrm{g} / \mathrm{ml}$ & Kambizi et al. (2007) \\
\hline $\begin{array}{l}\text { Anogeissus leiocarpa (DC.) Guill. and Perr. } \\
\text { (Combretaceae) }\end{array}$ & $L$ & Ethanol & Showed $50 \%$ inhibition of HSV1 and Equine HSV & Kudi and Myint, (1999) \\
\hline Bauhinia thonningii Schum. (Leguminosae) & $\mathrm{L}$ & Ethanol & $\begin{array}{l}\text { Showed total inhibition of HSV 1, Equine HSV, and } 75 \% \\
\text { inhibition of Bovine HSV }\end{array}$ & Kudi and Myint, (1999) \\
\hline Bidens pilosa L. (Compositae) & WP & Hot water & $\begin{array}{l}\text { Inhibited HSV- } 1 \text { with } \mathrm{ED}_{50} \text { of } 655.4 \mu \mathrm{g} / \mathrm{ml} \text { and for HSV- } \\
2 \text { with } \mathrm{ED}_{50} \text { of } 960 \mu \mathrm{g} / \mathrm{ml}\end{array}$ & Chiang et al. (2003) \\
\hline Centella asiatica (L.) Urb. (Apiaceae) & $\mathrm{AP}$ & Water & Inhibited HSV-1 with $\mathrm{Ec}_{50}$ of $362.40 \mu \mathrm{g} / \mathrm{ml}$ & Yoosook et al. (2000) \\
\hline Carissa spinarum L. (Apocynaceae) & $\mathrm{R}, \mathrm{B}$ & Water & Active against HSV with $\mathrm{CC}_{50}$ of $480 \mu \mathrm{g} / \mathrm{ml}$ & $\begin{array}{l}\text { Tolo et al. (2006), Kwena } \\
\text { (2014) }\end{array}$ \\
\hline Chironia krebsii Griseb. (Capparaceae) & $\mathrm{R}$ & DCM & $\begin{array}{l}\text { Active against HSV in the EC range of } 6.25-12.5 \mu \mathrm{g} / \mathrm{ml} \text {, } \\
\mathrm{SI}=2\end{array}$ & Beuscher et al. (1994) \\
\hline $\begin{array}{l}\text { Rotheca myricoides (Hochst.) Steane \& Mabb. } \\
\text { (Lamiaceae) }\end{array}$ & $L, R$ & Ethanol & Active against HSV with RF $10^{3}$ & $\begin{array}{l}\text { Vlietinck et al. (1995), } \\
\text { Sindambiwe et al. (1999) }\end{array}$ \\
\hline Clutia abyssinica Jaub. and Spach (Peraceae) & $\mathrm{L}$ & Ethanol & Active against HSV with RF of $10^{3}$ & Vlietinck et al. (1995) \\
\hline Combretum micranthum G.Don (Combretaceae) & $L$ & Ethanol & $\begin{array}{l}\text { Active against } \mathrm{HSV}-1 \text { with } \mathrm{EC}_{50} \text { of } 2 \mu \mathrm{g} / \mathrm{ml} \\
\text { Active against } \mathrm{HSV}-2 \text { with } \mathrm{EC}_{50} \text { of } 4 \mu \mathrm{g} / \mathrm{ml}\end{array}$ & Ferrea et al. (1993) \\
\hline $\begin{array}{l}\text { Crassocephalum macropappus (Sch.Bip. ex } \\
\text { A.Rich.) S.Moore (Compositae) }\end{array}$ & $\mathrm{L}$ & Ethanol & Active against HSV with RF of $10^{3}$ & Vlietinck et al. (1995) \\
\hline Detarium senegalense J.F.Gmel. (Leguminosae) & $L$ & Ethanol & $\begin{array}{l}\text { Inhibit Astrovirus HSV 1, Equine HSV at effective } \\
\text { concentration of } 2 \mathrm{mg} / \mathrm{ml}\end{array}$ & Kudi and Myint (1999) \\
\hline $\begin{array}{l}\text { Dichrostachys cinerea (L.) Wight \& Arn. } \\
\text { (Fabaceae) }\end{array}$ & $L$ & Ethanol & $\begin{array}{l}\text { Inhibit HSV 1, Equine HSV, at effective concentration of } \\
1 \mathrm{mg} / \mathrm{ml}\end{array}$ & Kudi and Myint (1999) \\
\hline $\begin{array}{l}\text { Dryopteris inaequalis (Schltdl.) Kuntze } \\
\text { (Dryopteriaceae) }\end{array}$ & WP & Ethanol & Active against herpes with $10^{3}$ viral titer factor reduction & Vlietinck et al. (1995) \\
\hline Erigeron aegyptiacus L. (Compositae) & $\mathrm{L}$ & Methanol & Active against HSV with MIC of $500 \mu \mathrm{g} / \mathrm{ml}$ & Anani et al. (2000) \\
\hline Eriosema montanum Baker f. (Fabaceae) & $\mathrm{L}$ & Ethanol & Active against HSV with $\mathrm{RF}=10^{4}$ & Cos et al. (2002a) \\
\hline Euphorbia hirta L. (Euphorbiaceae) & WP & & Active against HSV with RF $10^{3}$ & Vlietinck et al. (1995) \\
\hline Helichrysum foetidum (L.) Cass. (Compositae) & WP & Ethanol & Virucidal against HSV 1 with MVC >1/20 & Sindambiwe et al. (1999) \\
\hline $\begin{array}{l}\text { Neonotonia wightii (Wight \& Arn.) J.A.Lackey } \\
\text { (Fabaceae) }\end{array}$ & $L, S$ & Ethanol & Active against HSV with RF $10^{3}$ virus & Vlietinck et al. (1995) \\
\hline Guiera senegalensis J.F.Gmel. (Combretaceae) & $\mathrm{L}$ & Ethanol & Inhibits HSV1 and Equine HSV & Kudi and Myint, (1999) \\
\hline Guizotia Scabra (Vis.) Chiov. (Asteraceae) & $\mathrm{L}$ & Ethanol & Active against the HSV virus with RF of $10^{3}$ & Cos et al. (2002a) \\
\hline Houttuynia cordata Thunb. (Saururaceae) & & Hot water & $\begin{array}{l}\text { Inhibited replication of HSV. The } \text { EC }_{50} \text { of HSV-1 } \\
\text { was822.4 } \mu \mathrm{g} / \mathrm{ml} \text { and HSV-2 was } 362.5 \mu \mathrm{g} / \mathrm{ml} \text {. }\end{array}$ & Chiang et al. (2003) \\
\hline Ipomoea bonariensis Hook. (Convolvulaceae) & $\mathrm{AP}$ & Ethanol & $\begin{array}{l}\text { Showed true antiviral activity against HSV1 with RF of } \\
10 \text { and MVC of } 1 / 100\end{array}$ & Sindambiwe et al. (1999) \\
\hline Jasminum fluminense Vell. (Oleaceae) & $S$ & ethanol & Active against HSV from cc50-200 $\mu \mathrm{g} / \mathrm{ml}, \mathrm{SI}=2$ & Beuscher et al. (1994) \\
\hline Lannea humilis (Oliv.) Engl. (Anacardiaceae) & $\mathrm{B}$ & Ethanol & Inhibit HSV 1 and Equine HSV with EC of $1 \mathrm{mg} / \mathrm{ml}$ & Kudi and Myint, (1999) \\
\hline $\begin{array}{l}\text { Leonotis nepetaefolia var. africana (P.Beauv.) } \\
\text { J.K.Morton (Lamiaceae) }\end{array}$ & $\mathrm{F}$ & Ethanol & Active against HSV with RF of $10^{2}$ & Vlietinck et al. (1995) \\
\hline Maesa lanceolata Forssk. (Myrsinaceae) & $\mathrm{L}$ & Ethanol & Virucidal activity against HSV1 with MVC 1/400 & Sindambiwe et al. (1999) \\
\hline Moringa oleifera Lam. (Moringaceae) & $\mathrm{L}$ & Water & $\begin{array}{l}\text { Active against HSV- } 1 \text { with \%inhibition of } 43.2 \text { and HSV- } \\
2 \text { with \% inhibition of } 21.4\end{array}$ & Nasr-Eldin et al. (2018) \\
\hline $\begin{array}{l}\text { Markhamia lutea (Benth.) K.Schum. } \\
\text { (Bignoniaceae) }\end{array}$ & $R, L$ & Ethanol & Active against HSV with RF of $10^{3}$ & Vlietinck et al. (1995) \\
\hline Mitragyna inermis (Willd.) Kuntze (Rubiaceae) & $\mathrm{L}$ & Methanol & Active against HSV with EC from $50-100 \mu \mathrm{g} / \mathrm{ml} ; \mathrm{SI}=2$ & Beuscher et al. (1994) \\
\hline $\begin{array}{l}\text { Palisota hirsute (Thunb.) K.Schum. } \\
\text { (Commelinaceae) }\end{array}$ & $\mathrm{L}$ & Methanol & Active against HSV $(\mathrm{MIC}=62.5 \mu \mathrm{g} / \mathrm{ml})$ & Anani et al. (2000) \\
\hline Rubus rigidus Sm. (Rosaceae) & $L, R$ & Ethanol & Antiviral activity against HSV (RF of $10^{4}$ ) & Vlietinck et al. (1995) \\
\hline $\begin{array}{l}\text { Securidaca longepedunculata Fresen. } \\
\text { (Polygalaceae) }\end{array}$ & $\mathrm{R}$ & Methanol & Active against HSV with EC from 12.5-25 $\mu \mathrm{g} / \mathrm{ml} \mathrm{SI}=2$ & Beuscher et al. (1994) \\
\hline Sterculia setigera Delile (Sterculiaceae) & $L$ & Ethanol & $\begin{array}{l}\text { Showed total Inhibition of HSV } 1 \text { and Equine HSV with of } \\
1 \mathrm{mg} / \mathrm{ml}\end{array}$ & Kudi and Myint, (1999) \\
\hline
\end{tabular}

AP, areal part; B, Bark; L, leaf; SB, stem bark; R, root; RB, root bark; WP, whole plant; HSV, herpes simplex virus; DCM, dichloromethane; SI, Selective index; EC50, half maximal effective concentration; MVC, minimal virucidal concentration; $R F$, reduction factor of viral titre.

no currently available published study on Africa medicinal plants demonstrating clinical effectiveness. In contrast, China has developed several Chinese herbal medicines (CHM) and produced numerous clinical studies and publications. There is a daring absence of published studies on herbal medicine use in Africa in comparison to the actual magnitude of its practice. Many Africans are using one or another type of African traditional medicine either for prevention or treatment of COVID-19. 
TABLE 4 | Antiviral activity of African medicinal plants against poliovirus, astrovirus, coxsackievirus, Rift Valley fever virus, zika virus, measle, echovirus, yellow fiver virus, parvovirus, chikungunya virus, cytomegalovirus, CDV.

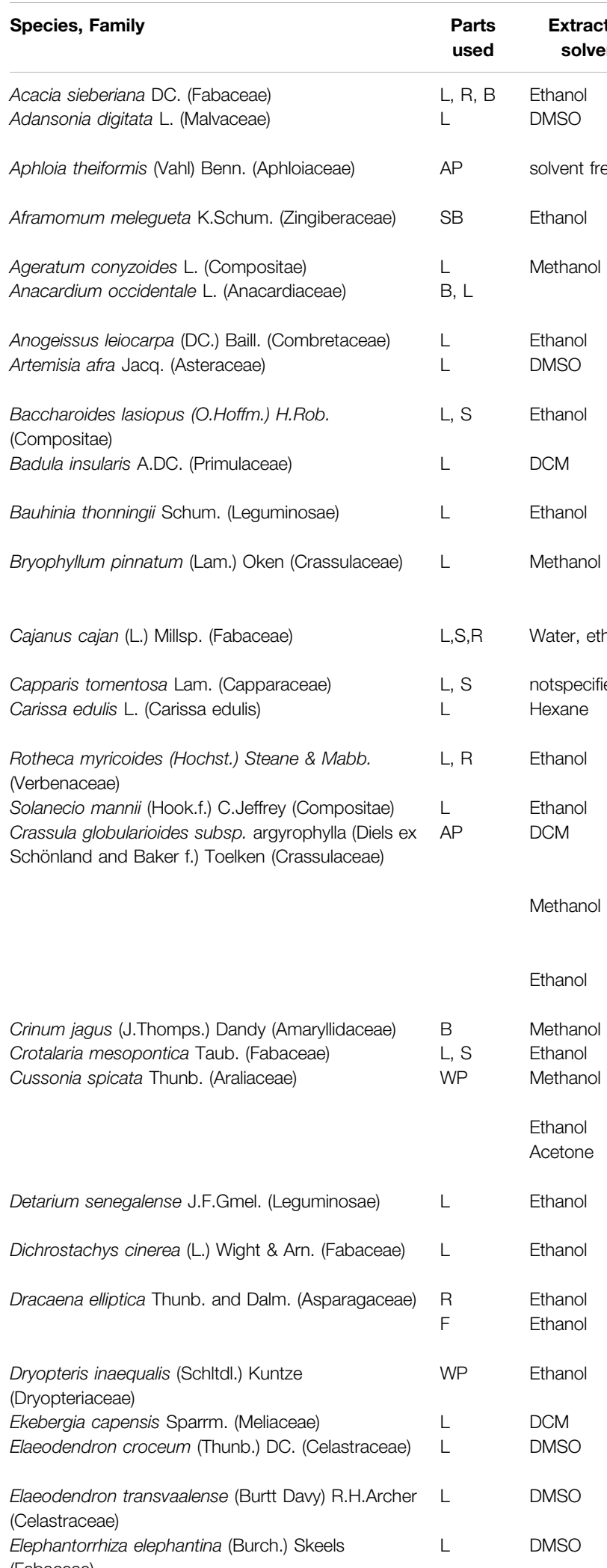

(Fabaceae)

Active against coxsackievirus with RF of $10^{5}$ Inhibited Rift Valley fever virus with DPPH EC50 Of $4.64 \mu \mathrm{g} / \mathrm{ml}$ and ABTS EC50 $5.04 \mu \mathrm{g} / \mathrm{ml}$ Inhibit zika virus entry into host cells atlC50 $=100 \mu \mathrm{g}$ and $\mathrm{CC} 50=3000 \mu \mathrm{g} / \mathrm{ml} ; \mathrm{SI}=30$

Active against Measles Virus with MIC $=125 \mu \mathrm{g} /$ mLandYellow Fiver Virus with MIC of $250 \mu \mathrm{g} / \mathrm{mL}$.

Active against Ecovirus with CC50 of $155.33 \mu \mathrm{g} / \mathrm{ml}$ Showed total inhibition of Poliovirus, Astrovirus, Bovine parvovirus, Canine parvovirus

Showed total inhibition of poliovirus andastrovirus Inhibited Rift Valley fever virus with DPPH EC50 Of $20.41 \mu \mathrm{g} / \mathrm{ml}$ and ABTS EC50 $16.39 \mu \mathrm{g} / \mathrm{ml}$ Active against coxsackie virus with of RF $10^{2}$

Active against rhinovirus type 2 with $E C$ range from $2.5-5 \mu \mathrm{g} / \mathrm{ml} \mathrm{SI}=2$

Showed total inhibition of Poliovirus andAstrovirus; $75 \%$ inhibition of Bovine parvovirus, Canine parvovirus Inhibited echovirus with $\mathrm{CC}_{50}$ of $125.47 \mu \mathrm{g} / \mathrm{ml} ; \mathrm{IC}_{50}$ againist $\mathrm{E} 7$ strainwas $3.13 \mu \mathrm{g} / \mathrm{ml}$; and $\mathrm{IC}_{50}$ against $\mathrm{E} 19$ strain was $2.03 \mu \mathrm{g} / \mathrm{ml}$

Active against coxsackie virus with RF of $10^{3}$

Active against coxsackie virus with RF of $10^{4.5}$ Active against FHV-1 and CDV with EC50 of 73.17 and 12.37 respectively

Active against coxsackie virus, with $\mathrm{RF} 10^{2}$

Active against Coxsackie with RF of $10^{3}$ Active against Rhinovirus with $\mathrm{EC}$ range from $6.25-25 \mu \mathrm{g} / \mathrm{ml}, \mathrm{SI}=4$; Poliovirus with EC range from $12.5-25 \mu \mathrm{g} / \mathrm{ml}, \mathrm{Sl}=2$

Active against Rhinovirus EC range from $6.25-25 \mu \mathrm{g} /$ $\mathrm{ml} \mu \mathrm{g} / \mathrm{ml} \mathrm{SI}=2$; Poliovirus EC range from 50-100 $\mu \mathrm{g} / \mathrm{ml}$ $\mathrm{SI}=2$

Active against rhinovirus with EC from 6.25-25 $\mu \mathrm{g} /$ $\mathrm{ml} \mu \mathrm{g} / \mathrm{ml}, \mathrm{Sl}=2$

Active against Echovirus with $\mathrm{CC}_{50}$ of $9.88 \mu \mathrm{g} / \mathrm{ml}$ polio virus with $\mathrm{RF}$ of $10^{3}$

Active against Coxsackievirus with $\mathrm{CC}_{50}$ of $117 \pm$ $11.5 \mu \mathrm{g} / \mathrm{ml}$ and EC50 of $14.6 \mu \mathrm{g} / \mathrm{ml} ; \mathrm{SI}=8$ $\mathrm{CC} 50=39 \pm 12.6 \mu \mathrm{g} / \mathrm{ml}$ EC50 $=4.8 \mu \mathrm{g} / \mathrm{ml}, \mathrm{SI}=8$ Active against Coxsackie virus: Acetone $\mathrm{CC}_{50}=108 \pm$ $2.4 \mu \mathrm{g} / \mathrm{ml} \mathrm{m}, \mathrm{EC} 50=13.5 \mu \mathrm{g} / \mathrm{ml} \mathrm{SI}=8$

Inhibit Poliovirus, Astrovirus, Bovine parvovirus, Canine parvovirus with an effective concentration of $2 \mathrm{mg} / \mathrm{ml}$ Inhibit Poliovirus Astrovirus, Bovine parvovirus, Canine parvovirus with an effective concentration of $1 \mathrm{mg} / \mathrm{ml}$ Active against coxsackie with RF $10^{3}$

Active against polio virus and coxsackie with $10^{4}$ and $10^{3}$ viral titer reduction factor respectively

Active against poliovirus with $10^{3}$ viral titer factor reduction

Active agaist CDV with EC50 of 30.93 respectively Inhibited Rift Valley fever virus with DPPH EC50 of $6 \mu \mathrm{g} /$ $\mathrm{ml}$ and ABTS EC50 $4.12 \mu \mathrm{g} / \mathrm{ml}$ Inhibited Rift Valley fever virus with DPPH EC50 of $11.64 \mu \mathrm{g} / \mathrm{ml}$ and ABTS EC50 $15 \mu \mathrm{g} / \mathrm{ml}$ Inhibited Rift Valley fever virus with DPPH EC50 of $6.54 \mu \mathrm{g} / \mathrm{ml}$ and ABTS EC50 $7.4 \mu \mathrm{g} / \mathrm{ml}$
References

Vlietinck et al. (1995)

More et al. (2021)

Clain et al. (2018)

Ojo et al. (2009)

Ogbole et al. (2018)

Kudi and Myint, (1999)

Kudi and Myint, (1999)

More et al. (2021)

Vlietinck et al. (1995)

Beuscher et al. (1994)

Kudi and Myint, (1999)

Ogbole et al. (2018)

Vlietinck et al. (1995), Nwodo et al. (2011) Vlietinck et al. (1995)

More et al. (2021)

Vlietinck et al. (1995), Sindambiwe et al. (1999) Vlietinck et al. (1995)

Beuscher et al. (1994)

Beuscher et al. (1994)

Beuscher et al. (1994)

Ogbole et al. (2018)

Vlietinck et al. (1995)

Sultana, (2011)

Kudi and Myint, (1999)

Kudi and Myint, (1999)

Vlietinck et al. (1995)

Vlietinck et al. (1995)

More et al. (2021)

More et al. (2021)

More et al. (2021)

More et al. (2021)

(1)

(Continued on following page) 
TABLE 4 | (Continued) Antiviral activity of African medicinal plants against poliovirus, astrovirus, coxsackievirus, Rift Valley fever virus, zika virus, measle, echovirus, yellow fiver virus, parvovirus, chikungunya virus, cytomegalovirus, CDV.

\begin{tabular}{|c|c|c|c|c|}
\hline Species, Family & $\begin{array}{l}\text { Parts } \\
\text { used }\end{array}$ & $\begin{array}{c}\text { Extracting } \\
\text { solvent }\end{array}$ & Activity & References \\
\hline Eriosema montanum Baker f. (Fabaceae) & $L$ & Ethanol & $\begin{array}{l}\text { Active against Coxsackie virus with RF of } 10^{3} \text {, measles } \\
\text { with RF } 10^{2} \text {, Poliovirus with RF of } 10^{3} \text {, SF with RF of } 10^{4} \\
\text { andVSV with RF of } 10^{2}\end{array}$ & Cos et al. (2002a) \\
\hline Erythrina abyssinicaDC.(Fabaceae) & $S, R, L$ & Ethanol & $\begin{array}{l}\text { Active against polio, semiliki forest and measles virus } \\
\text { with RF of } 10^{4}\end{array}$ & Vlietinck et al. (1995) \\
\hline Euclea natalensis A.DC. (Ebenaceae) & $L$ & DMSO & $\begin{array}{l}\text { Inhibited Rift Valley fever virus with DPPH EC } \text { E }_{50} \text { of } \\
5.3 \mu \mathrm{g} / \mathrm{ml} \text { and ABTS } \mathrm{EC}_{50} \text { of } 5.00 \mu \mathrm{g} / \mathrm{ml}\end{array}$ & More et al. (2021) \\
\hline Helichrysum abietifolium Humbert (Asteraceae) & $L$ & DMSO & $\begin{array}{l}\text { Inhibited Rift Valley fever virus with DPPH EC } \mathrm{EC}_{50} \text { of } \\
8.25 \mu \mathrm{g} / \mathrm{ml} \text { and ABTS } \mathrm{EC}_{50} 11.4 \mu \mathrm{g} / \mathrm{ml}\end{array}$ & More et al. (2021) \\
\hline Euphorbia grantii Oliv. (Euphorbiaceae) & $L, S$ & Ethanol & $\begin{array}{l}\text { Active against poliovirus and Coxsackie virus with RF } \\
\text { of } 10^{5}\end{array}$ & Vlietinck et al. (1995) \\
\hline Euphorbia hirta L. (Euphorbiaceae) & WP & Not specified & $\begin{array}{l}\text { Active against poliovirus with RF of } 10^{5} \text { and against } \\
\text { Coxsackie virus with RF of } 10^{3}\end{array}$ & Vlietinck et al. (1995) \\
\hline Guiera senegalensis J.F.Gmel. (Combretaceae) & $\mathrm{L}$ & Ethanol & Inhibits poliovirus & Kudi and Myint, (1999) \\
\hline Guizotia Scabra (Vis.) Chiov. (Asteraceae) & $L$ & Ethanol & $\begin{array}{l}\text { Active against the Coxsackie and Poliovirus with RF } \\
\text { of } 10^{3}\end{array}$ & Cos et al. (2002a) \\
\hline \multirow[t]{2}{*}{$\begin{array}{l}\text { Heteromorpha arborescens (Spreng.) Cham. and } \\
\text { Schltdl. (Apiaceae) }\end{array}$} & $\mathrm{RB}$ & Methanol & $\begin{array}{l}\text { Active against Poliovirus with EC from } 10-25 \mu \mathrm{g} / \mathrm{ml} \mathrm{SI} \\
=2.5\end{array}$ & Beuscher et al. (1994) \\
\hline & $\mathrm{RB}$ & Ethanol & $\begin{array}{l}\text { Active against Poliovirus with EC from } 12.5-50 \mu \mathrm{g} / \mathrm{ml} \mathrm{SI} \\
=4\end{array}$ & Beuscher et al. (1994) \\
\hline Hibiscus sabdariffa L. (Malvaceae) & $\mathrm{L}$ & Ethanol & $\begin{array}{l}\text { Active against measles virus at with EC from } \\
10-15 \mathrm{mg} / \mathrm{ml}\end{array}$ & Sunday et al. (2010) \\
\hline Helichrysum cymosum (L.) D.Don (Compositae) & WP & Ethanol & $\begin{array}{l}\text { Showed virucidal activity against Semiliki forest virus A7 } \\
\text { with RF of } 10^{3}\end{array}$ & Sindambiwe et al. (1999) \\
\hline \multirow[t]{2}{*}{$\begin{array}{l}\text { Holarrhena pubescens Wall. ex G.Don } \\
\text { (Appocynaceae) }\end{array}$} & SB & $\mathrm{DCM}$ & $\begin{array}{l}\text { Active against rhinovirus with EC range from } 10-25 \mu \mathrm{g} / \\
\mathrm{ml} \mathrm{SI}=2.5\end{array}$ & Beuscher et al. (1994) \\
\hline & & $\mathrm{EtOH}$ & $\begin{array}{l}\text { Active against rhinovirus with EC range from } 50-25 \mu \mathrm{g} / \\
\mathrm{ml} \mathrm{SI}=2.5\end{array}$ & Beuscher et al. (1994) \\
\hline $\begin{array}{l}\text { Ipomoea asarifolia (Desr.) Roem. and Schult. } \\
\text { (Convolvulaceae) }\end{array}$ & $L$ & Methanol & $\begin{array}{l}\text { Showed potent antiviral activity against Echo virus With } \\
\mathrm{CC}_{50} \text { of } 84.21 \mu \mathrm{g} / \mathrm{ml}\end{array}$ & Ogbole et al. (2018) \\
\hline Ipomoea bonariensis Hook. (Convolvulaceae) & $\mathrm{AP}$ & Ethanol & $\begin{array}{l}\text { Showed virucidal effect against vesicular stomatitis virus } \\
\text { T2 (VSV T2) with RF of } 103\end{array}$ & Sindambiwe et al. (1999) \\
\hline \multirow[t]{4}{*}{ Jasminum fluminense Vell. (Appearance) } & S & $\mathrm{DCM}$ & $\begin{array}{l}\text { Active against Poliovirus with EC range of } 100-200 \mu g / \\
\mathrm{ml}, \mathrm{SI}=2\end{array}$ & Beuscher et al. (1994) \\
\hline & & Methanol & $\begin{array}{l}\text { Active against Poliovirus with EC range of } 100-400 \mu g / \\
\mathrm{ml}, \mathrm{SI}=4\end{array}$ & Beuscher et al. (1994) \\
\hline & & Ethanol & $\begin{array}{l}\text { Active against Poliovirus with EC range of } 50-1200 \mu \mathrm{g} / \\
\mathrm{ml}, \mathrm{SI}=24\end{array}$ & Beuscher et al. (1994) \\
\hline & & Methanol & $\begin{array}{l}\text { Active against rhinovirus with EC range of } 50-100 \mu \mathrm{g} / \\
\mathrm{ml}, \mathrm{SI}=2\end{array}$ & Beuscher et al. (1994) \\
\hline Khaya senegalensis (Desv.) A.Juss. (Meliaceae) & $\mathrm{B}$ & Ethanol & Inhibit Poliovirus, Astrovirus with EC of 2 mg/ml & Kudi and Myint, (1999) \\
\hline \multirow[t]{3}{*}{ Labourdonnaisia calophylloides Bojer (Sapotaceae) } & $\mathrm{L}$ & DCM & $\begin{array}{l}\text { Active against Poliovirus with EC range from 5-200 } \mu \mathrm{g} / \\
\mathrm{ml}, \mathrm{SI}=40\end{array}$ & Beuscher et al. (1994) \\
\hline & & Ethanol & $\begin{array}{l}\text { Active against Poliovirus with EC range from } 12.5 \text { to } \\
25 \mu \mathrm{g} / \mathrm{ml}, \mathrm{SI}=2\end{array}$ & Beuscher et al. (1994) \\
\hline & & Ethanol & $\begin{array}{l}\text { Active against rhinovirus with EC range from } 25-50 \mathrm{SI} \\
=2\end{array}$ & Beuscher et al. (1994) \\
\hline Laggera brevipes Oliv. and Hiern (Fabaceae) & $L, S, F$ & Ethanol & $\begin{array}{l}\text { Active against poliovirus and Coxseckie virus with RF of } \\
10^{3} \text { and } 10^{4} \text { respectively }\end{array}$ & Vlietinck et al. (1995) \\
\hline Lannea humilis (Oliv.) Engl. (Anacardiaceae) & B & Ethanol & Inhibit Poliovirus and Astrovirus with EC of 1 mg/ml & Kudi and Myint, (1999) \\
\hline Leonotis nepetaefolia (L.) R.Br. (Lamiaceae) & $\mathrm{F}$ & Ethanol & Active against coxsakievirus withRF of $10^{2}$ & Vlietinck et al. (1995) \\
\hline Lippia multiflora Moldenke (Verbenaceae) & $\mathrm{L}$ & Ethanol & Active against Echovirus with $\mathrm{CC}_{50}$ of $112.07 \mu \mathrm{g} / \mathrm{ml}$ & Ogbole et al. (2018) \\
\hline Maesa lanceolata Forssk. (Myrsinaceae) & $L$ & Ethanol & $\begin{array}{l}\text { Virucidal activity against Measles vurus with MVC of } \\
1 / 800\end{array}$ & Sindambiwe et al. (1999) \\
\hline Macaranga barteri Müll.Arg. (Euphorbiaceae) & $\mathrm{L}$ & Methanol & $\begin{array}{l}\text { Active against serotypes of enterovirus (E7, E13 and } \\
\text { E19) with } \mathrm{CC}_{50} 0 \text { of } 0.27 \mathrm{\mu g} / \mathrm{ml}\end{array}$ & Ogbole et al. (2018) \\
\hline Macaranga kilimandscharica Pax (Euphorbaceae) & $\mathrm{L}$ & Ethanol & Active against Poliovirus with RF of $10^{3}$ & Vlietinck et al. (1995) \\
\hline \multirow[t]{3}{*}{ Mitragyna inermis (Willd.) Kuntze (Rubiaceae) } & $\mathrm{L}$ & DCM & $\begin{array}{l}\text { Active against Poliovirus with EC from } 12.5-25 \mu \mathrm{g} / \mathrm{ml}, \mathrm{SI} \\
=2\end{array}$ & Beuscher et al. (1994) \\
\hline & & Methanol & $\begin{array}{l}\text { Active against Poliovirus with EC from } 25-200 \mu \mathrm{g} / \mathrm{ml}, \mathrm{SI} \\
=8\end{array}$ & Beuscher et al. (1994) \\
\hline & & $\mathrm{DCM}$ & $\begin{array}{l}\text { Active against rhinovirus With EC from } 12.5-25 \mu \mathrm{g} / \mathrm{ml} \\
\text { (Continue }\end{array}$ & $\begin{array}{l}\text { Beuscher et al. (1994) } \\
\text { d on following page) }\end{array}$ \\
\hline
\end{tabular}


TABLE 4 | (Continued) Antiviral activity of African medicinal plants against poliovirus, astrovirus, coxsackievirus, Rift Valley fever virus, zika virus, measle, echovirus, yellow fiver virus, parvovirus, chikungunya virus, cytomegalovirus, CDV.

\begin{tabular}{|c|c|c|c|c|}
\hline Species, Family & $\begin{array}{l}\text { Parts } \\
\text { used }\end{array}$ & $\begin{array}{l}\text { Extracting } \\
\text { solvent }\end{array}$ & Activity & References \\
\hline Mondia whitei (Hook.f.) Skeels (Periplocaceae) & $\mathrm{L}$ & Methanol & Active against echovirus with CC50 of $132.50 \mu \mathrm{g} / \mathrm{ml}$ & Ogbole et al. (2018) \\
\hline \multirow[t]{4}{*}{ Myonima violacea (Lam.) Verdc. (Rubiaceae) } & $\mathrm{L}$ & $\mathrm{DCM}$ & $\begin{array}{l}\text { Active against Poliovirus with EC from } 6.3-50 \mu \mathrm{g} / \mathrm{ml}, \mathrm{SI} \\
=8\end{array}$ & Beuscher et al. (1994) \\
\hline & & Ethanol & $\begin{array}{l}\text { Active against Poliovirus with EC from } 25-50 \mu \mathrm{g} / \mathrm{ml}, \mathrm{SI} \\
=2\end{array}$ & Beuscher et al. (1994) \\
\hline & & $\mathrm{DCM}$ & $\begin{array}{l}\text { Active against rhinovirus with EC from } 20-50 \mu \mathrm{g} / \mathrm{ml}, \mathrm{SI} \\
=2\end{array}$ & Beuscher et al. (1994) \\
\hline & & Ethanol & Active against rhinovirus EC of $50-60 \mu \mathrm{g} / \mathrm{ml} \mathrm{SI}=2$ & Beuscher et al. (1994) \\
\hline Pavetta ternifolia Hiern. (Rubiace) & $L$ & Ethanol & $\begin{array}{l}\text { Showed virucidal activities against enveloped viruses } \\
\text { with MVC }>1 / 20 \text { and slightly active extracellularly against } \\
\text { VSV with MVC }=1 / 20\end{array}$ & Sindambiwe et al. (1999) \\
\hline Plantago palmate Lam. (Plantaginaceae) & $\mathrm{L}$ & Ethanol & Active against coxsakie (RF $10^{3}$, polio (RF $10^{1.5)}$ virus & Vlietinck et al. (1995) \\
\hline Plumbago zeylanica L. (Plumbaginaceae) & $\mathrm{L}$ & Hexane & Active against CDV with EC50 of 11.73 & Bagla et al. (2012) \\
\hline \multirow[t]{2}{*}{ Polygala stenopetala Klotzsch (Polygalaceae) } & $\mathrm{AP}$ & DCM & $\begin{array}{l}\text { Active against Poliovirus with EC range from } \\
100-400 \mu \mathrm{g} / \mathrm{ml}, \mathrm{SI}_{=} 4\end{array}$ & Beuscher et al. (1994) \\
\hline & & Ethanol & $\begin{array}{l}\text { Active against Poliovirus with EC range from } \\
100-200 \mu \mathrm{g} / \mathrm{ml}, \mathrm{SI}=2\end{array}$ & Beuscher et al. (1994) \\
\hline \multirow[t]{6}{*}{ Polygala virgate Polygala virgate (Polygalaceae) } & $\mathrm{AP}$ & DCM & $\begin{array}{l}\text { Active against Poliovirus with EC range from } \\
12.5-100 \mu \mathrm{g} / \mathrm{ml}, \mathrm{SI}=8\end{array}$ & Beuscher et al. (1994) \\
\hline & & Methanol & $\begin{array}{l}\text { Active against Poliovirus with EC range from } 25-100 \mu \mathrm{g} / \\
\mathrm{ml}, \mathrm{SI}=4\end{array}$ & Beuscher et al. (1994) \\
\hline & & Ethanol & $\begin{array}{l}\text { Active against Poliovirus with EC from } 50-400 \mu \mathrm{g} / \mathrm{ml}, \mathrm{SI} \\
=4\end{array}$ & Beuscher et al. (1994) \\
\hline & & DCM & $\begin{array}{l}\text { Active against rhinovirus with EC range from } \\
12.5-25 \mu \mathrm{g} / \mathrm{ml}, \mathrm{SI}=2\end{array}$ & Beuscher et al. (1994) \\
\hline & & Methanol & $\begin{array}{l}\text { Active against rhihinovirus with EC range from } \\
25-100 \mu \mathrm{g} / \mathrm{ml}, \mathrm{SI}=4\end{array}$ & Beuscher et al. (1994) \\
\hline & & ethanol & $\begin{array}{l}\text { Active against rhinovirus with EC range from 50-200 } \mathrm{\mu g} / \\
\mathrm{ml}, \mathrm{SI}=4\end{array}$ & Beuscher et al. (1994) \\
\hline Polygonum pulchrum (Blume) Soják (Polygalaceae) & $\mathrm{R}$ & Ethanol & Active against Coxsackievirus with $\mathrm{RF} 10^{3}$ & Vlietinck et al. (1995) \\
\hline Prunus africana (Hook.f.) Kalkman (Rosaceae) & SB & Water & Active against $\mathrm{HCMV}$ with $\mathrm{EC}_{50}$ of $80 \mu \mathrm{g} / \mathrm{ml}$ & Tolo et al. (2007) \\
\hline $\begin{array}{l}\text { Psiloxylon mauritianum (Bouton ex Hook.f.) Baill. } \\
\text { (Myrtaceae) }\end{array}$ & $\mathrm{AP}$ & $\begin{array}{l}\text { Solvent-free } \\
\text { microwave }\end{array}$ & $\begin{array}{l}\text { Active against Zika and Dengue virus with } \mathrm{CC}_{50} \text { of } \\
1044 \mathrm{~g} / \mathrm{ml} \text { (Vero cells); } \mathrm{CC}_{50} \text { of } 657 \mathrm{~g} / \mathrm{ml} \text { (A549 cells); } \\
\mathrm{CC}_{50} \text { of } 353 \mathrm{~g} / \mathrm{ml} \text { (keratinocytes); } \mathrm{CC}_{50} \text { of } 820 \mathrm{~g} / \mathrm{ml} \\
\text { (fibroblast); } \mathrm{SI}=53.5\end{array}$ & Clain et al. (2018) \\
\hline \multirow[t]{3}{*}{ Pterocarpus angolensis DC. (Fabaceae) } & SB & Methanol & $\begin{array}{l}\text { Active against Poliovirus with EC range from } 50-100 \mu \mathrm{g} / \\
\mathrm{ml}, \mathrm{SI}=2\end{array}$ & Beuscher et al. (1994) \\
\hline & & Ethanol & $\begin{array}{l}\text { Active against Poliovirus with EC range from } 50-100 \mu \mathrm{g} / \\
\mathrm{ml}, \mathrm{SI}=2\end{array}$ & Beuscher et al. (1994) \\
\hline & & Ethanol & $\begin{array}{l}\text { Active against rhinovirus with EC range from } \\
12.5-25 \mu \mathrm{g} / \mathrm{ml}, \mathrm{SI}=2\end{array}$ & Beuscher et al. (1994) \\
\hline Searsia pyroides (Burch.) Moffett (Anacardiaceae) & $L, R$ & Ethanol & $\begin{array}{l}\text { Antiviral activity against Semiliki forest and } \\
\text { Coxsackievirus with RF of } 10^{4}\end{array}$ & Vlietinck et al. (1995) \\
\hline Rubus rigidus Sm. (Rosaceae) & $L, R$ & Ethanol & $\begin{array}{l}\text { Antiviral activity against Semiliki forest virus } \\
\text { Coxsackievirus with RF of } 10^{4}\end{array}$ & Vlietinck et al. (1995) \\
\hline \multirow[t]{2}{*}{ Securidaca longepedunculata Oliver (Polygalaceae) } & $\mathrm{R}$ & DCM & $\begin{array}{l}\text { Active against poliovirus with EC from } 5-10 \mu \mathrm{g} / \mathrm{ml}, \mathrm{SI} \\
=2\end{array}$ & Beuscher et al. (1994) \\
\hline & & Methanol & $\begin{array}{l}\text { Active against poliovirus with EC from } 5-10 \mu \mathrm{g} / \mathrm{ml}, \mathrm{SI} \\
=2\end{array}$ & \\
\hline Senna siamea (Lam.) H.S.Irwin \& Barneby (Fabaceae) & $\mathrm{B}$ & Methanol & $\begin{array}{l}\text { Active against poliovirus with a ratio of } C_{50} \text { to } I_{50}= \\
0.0019\end{array}$ & Ogbole et al. (2013) \\
\hline Senna singueana (Delile) Lock (Leguminosae) & $\mathrm{L}$ & Not specified & Inhibit Poliovirus, Astrovirus, Bovine parvovirus & Kudi and Myint, (1999) \\
\hline Sideroxylon puberulum A.DC. (Sapotaceae) & $L$ & $\mathrm{DCM}$ & $\begin{array}{l}\text { Active against poliovirus with EC range from 10-50 } \mu \mathrm{g} / \\
\mathrm{ml} \mathrm{SI},=5\end{array}$ & Beuscher et al. (1994) \\
\hline Solanum incanum L. (Solanaceae) & $\mathrm{R}, \mathrm{F}$ & Ethanol & Antiviral activity against Coxsackievirus with RF of $10^{4}$ & Vlietinck et al. (1995) \\
\hline Spondias dulcis Parkinson (Anacardiaceae) & $B, L$ & Methanol & Active against Echovirus with $\mathrm{CC}_{50}$ of $53.33 \mu \mathrm{g} / \mathrm{ml}$ & Ogbole et al. (2018) \\
\hline Steganotaenia araliacea Hochst. (Apiaceae) & $\mathrm{R}$ & Methanol & $\begin{array}{l}\text { Active against rhinovirus with EC range from } 5-10 \mu \mathrm{g} / \\
\mathrm{ml}, \mathrm{SI}=2\end{array}$ & Beuscher et al. (1994) \\
\hline Sterculia setigera Delile (Sterculiaceae) & $L$ & Ethanol & $\begin{array}{l}\text { Inhibit Poliovirus, Astrovirus, Bovine parvovirus, Canine } \\
\text { parvovirus with a total inhibition at EC of } 1 \mathrm{mg} / \mathrm{ml}\end{array}$ & Kudi and Myint, (1999) \\
\hline Sutherlandia frutescens (L.) R.Br. (Fabaceae) & $L$ & DMSO & $\begin{array}{l}\text { Inhibited Rift Valley fever virus with DPPH EC } \mathrm{C}_{50} \text { of } \\
32.2 \mu \mathrm{g} / \mathrm{ml} \text { and ABTS } \mathrm{EC}_{50} \text { of } 42.3 \mu \mathrm{g} / \mathrm{ml}\end{array}$ & More et al. (2021) \\
\hline
\end{tabular}

(Continued on following page) 
TABLE 4 | (Continued) Antiviral activity of African medicinal plants against poliovirus, astrovirus, coxsackievirus, Rift Valley fever virus, zika virus, measle, echovirus, yellow fiver virus, parvovirus, chikungunya virus, cytomegalovirus, CDV.

\begin{tabular}{|c|c|c|c|c|}
\hline Species, Family & $\begin{array}{l}\text { Parts } \\
\text { used }\end{array}$ & $\begin{array}{l}\text { Extracting } \\
\text { solvent }\end{array}$ & Activity & References \\
\hline $\begin{array}{l}\text { Tabernaemontana ventricosa Hochst. ex A.DC. } \\
\text { (Apocynaceae) }\end{array}$ & $\mathrm{L}$ & Methanol & $\begin{array}{l}\text { Antiviral activity against poliovirus with } \mathrm{CC}_{50} \text { of } 0.1 \pm \\
0.07 \mu \mathrm{g} / \mathrm{ml} \text { and } \mathrm{EC}_{50} \text { of } 0.05 \mu \mathrm{g} / \mathrm{ml} ; \mathrm{SI}=2\end{array}$ & Mehrbod et al. (2018) \\
\hline Terminalia ivorensisA.Chev. (Combretaceae) & $\mathrm{B}$ & Methanol & Active against Echovirus with $\mathrm{CC}_{50}$ of $12.14 \mu \mathrm{g} / \mathrm{ml}$ & Ogbole et al. (2018) \\
\hline Tetracera alnifolia Willd. (Dilieniaceae) & $\mathrm{L}$ & Methanol & Active against echovirus $\mathrm{CC}_{50}$ of $147.8 \mu \mathrm{g} / \mathrm{ml}$ & Ogbole et al. (2018) \\
\hline $\begin{array}{l}\text { Tabernaemontana ventricosa Hochst. ex A.DC. } \\
\text { (Apocynaceae) }\end{array}$ & $L$ & Methanol & $\begin{array}{l}\text { Active against poliovirus with } \mathrm{CC}_{50} \text { of } 0.1 \pm 0.07 \mu \mathrm{g} / \mathrm{ml} \text {; } \\
\mathrm{EC} 50 \text { of } 0.05 \mu \mathrm{g} / \mathrm{ml} ; \mathrm{SI}=2\end{array}$ & Mehrbod et al. (2018) \\
\hline Terminalia ivorensis A.Chev. (Combretaceae) & $\mathrm{B}$ & Methanol & Active against Echovirus withCC $C_{50}=12.14 \mu \mathrm{g} / \mathrm{ml}$ & Ogbole et al. (2018) \\
\hline Tetracera alnifolia Willd. (Dilieniaceae) & $\mathrm{L}$ & Methanol & Active against Echovirus with $\mathrm{CC}_{50}$ of $147.8 \mu \mathrm{g} / \mathrm{ml}$ & Ogbole et al. (2018) \\
\hline $\begin{array}{l}\text { Voacanga Africana Stapf ex Scott-Elliot } \\
\text { (Apocynaceae) }\end{array}$ & $\mathrm{RB}$ & Water & Active against Chikungunya viral disease & Ndhlala et al. (2013) \\
\hline $\begin{array}{l}\text { Vernoniastrum aemulans (Vatke) H.Rob. } \\
\text { (Compositae) }\end{array}$ & $\mathrm{L}$ & Ethanol & Active against Poliovirus with RF of $10^{4}$ & Vlietinck et al. (1995) \\
\hline Vernonia amygdalina Del. (Compositae) & $\mathrm{F}$ & Ethanol & Active against poliovirus with $\mathrm{RF}$ of $10^{3}$ & \\
\hline Vitellaria paradoxa C.F.Gaertn. (Sapotaceae) & $\mathrm{B}$ & Ethanol & $50 \%$ inhibition of Poliovirus and Astrovirus & $\begin{array}{l}\text { Kudi and Myint (1999), } \\
\text { Ogbole et al. (2013) }\end{array}$ \\
\hline \multirow[t]{4}{*}{ Xanthocercis madagascariensis Baill. (Fabaciae) } & $\mathrm{L}$ & DCM & $\begin{array}{l}\text { Active against poliovirus with EC from } 25-50 \mu \mathrm{g} / \mathrm{ml} \text {; SI } \\
=2\end{array}$ & Beuscher et al. (1994) \\
\hline & & Methanol & $\begin{array}{l}\text { Active against poliovirus with EC from } 25-100 \mu \mathrm{g} / \mathrm{ml} ; \mathrm{SI} \\
=4\end{array}$ & \\
\hline & & Ethanol & $\begin{array}{l}\text { Active against poliovirus with EC from } 500-1000 \mu \mathrm{g} / \mathrm{ml} \text {; } \\
\mathrm{SI}=2\end{array}$ & \\
\hline & & Methanol & $\begin{array}{l}\text { Active against rhinovirus with EC from } 60 \text { to } 80 \mu \mathrm{g} / \mathrm{ml} \text {; SI } \\
=1.6\end{array}$ & \\
\hline Zanha Africana (Radlk.) Exell (Sapindaceae) & $\mathrm{RB}$ & DCM & Active against poliovirus with EC from $12.5-25, \mathrm{SI}=2$ & \\
\hline Zephyranthes candida (Lindl.) Herb. (Amaryllidaceae) & WP & Methanol & $\begin{array}{l}\text { Active against poliovirus with the ratio of } C_{50} \text { to } I_{50} \\
0.21 \mu \mathrm{g} / \mathrm{ml}\end{array}$ & Ogbole et al. (2013) \\
\hline Ziziphus mucronataWilld. (Rhamnaceae) & $L$ & Ethanol & $\begin{array}{l}75 \% \text { inhibition Poliovirus and Astrovirus with EC of } \\
2 \mathrm{mg} / \mathrm{ml}\end{array}$ & Kudi and Myint, (1999) \\
\hline
\end{tabular}

$A P$, areal part; B, bark; L, leaf; SB, stem bark; R, root; RB, root bark; WP, whole plant; HSV, herpes simplex virus; HCMV, human cytomegalovirus; RSV, respiratory syncytial virus; DPPH, 2,2-diphenyl-1-picrylhydrazayl; ABTS, 2,2 azino-bis(3-ethaylbenzothiazoline-6-sulfonic acid); DCM, dichloromethane; DMSO, dimethyl sulfoxide; SI, selective index; CC 50 , the 50\% cytotoxic concentration; $E C_{50}$, Half maximal effective concentration; $I C_{50}$, the half-maximal inhibitory concentration; $F$, reduction factor of viral titre; CDV, canine distemper virus.

For example, Madagascar produced an herbal drink from Artemisia annua called COVID Organics which was even exported abroad (Cambaza, 2020). The anecdotal use of this product resulted in exaggerated claims of their efficacies that are not evidence-based. This calls for the urgent need for further research on this as well as all other herbal formulations on their efficacy through randomized controlled trials and identify their active ingredients, develop proven formulations and dosing protocols, and define pharmacokinetics, toxicology, and safety to enable drug development. Derivatives from the herb Artemisia annua have been used for the treatment of fevers, malaria, and respiratory tract infections. The WHO has offered to support the design of a study to assess the efficacy, safety, and dosage formulation of herbal formulations that may be useful against COVID-19 (Muhammad, 2020). The WHO is currently helping the validation of some traditional medicine through clinical trials for the treatment of COVID-19 (Tih, 2020).

Studies on TM use for COVID-19 produced many publications of which four were systematic reviews and metaanalyses entirely based on CHM (Liu et al., 2006; Fan et al., 2020; Liu et al., 2020; Xiong et al., 2020) and other systematic reviews and meta-analyses were not CHM (Ang et al., 2020). Traditional medicine is being used to control coronavirus alone or in a combination with western medicine. A recent systematic review and meta-analysis of randomized controlled trials included seven randomized controlled trials and compared combined therapy of herbal medicine with Western medicine and western medicine alone (Ang et al., 2020). This demonstrated the potential role of herbal medicine in treating and/or managing COVID-19 (Ang et al., 2020). The other study which included 12 randomized controlled trials and one quasi-RCT with A total of 640 SARS-CoV-2 patients and 12 Chinese herbs did not indicate a significant difference in Chinese herbs combined with Western medicines versus Western medicines alone (Liu et al., 2006). Yet hundreds of Chinese traditional medicines had been widely used for the treatment of SARS and currently, it's being used for SARSCoV-2 (Shahrajabian et al., 2020). A recent review conducted by Attah et al. (2021) summarized 17 African medicinal plants studied against Covid-19 with viral protein targeted. The medicinal plants listed targeted SARS-Cov-2 3CLpro and ACE2.

An in silico screening was conducted on 62 alkaloids and 100 terpenoids from African medicinal plants against coronavirus 3chymotrypsin-like protease (3CL ${ }^{\text {pro }}$ ), a highly defined hit-list of seven compounds. Furthermore, four nontoxic, druggable plant- 
derived alkaloids and terpenoids that bind to the receptorbinding site and catalytic dyad of SARS-CoV-2 3CL ${ }^{\text {pro }}$ were identified. More than half of the selected top 20 alkaloids and terpenoids had a binding affinity for the $3 \mathrm{CL}^{\text {pro }}$ of the SARScoronaviruses that surpassed reference inhibitors. The 6oxoisoiguesterin from Bisnorterpenes had the highest binding affinity to the $3 \mathrm{CL}^{\text {pro }}$ of SARS-CoV-2 while 20 -epi-isoiguesterinol from Bisnorterpenes, isoiguesterin from Bisnorterpenes, 20epibryonolic acid from Cogniauxia podolaena was the top docked compounds to $3 \mathrm{CL}^{\text {pro }}$ of SARS-CoV and MERS-CoV. The study revealed that natural agents from the alkaloids and terpenoids class of compounds are capable of inhibiting the $3 \mathrm{CL}^{\text {pro }}$ with a high inhibitory pattern to both SARS-CoV-2 and SARS-CoV (Gyebi et al., 2021). Moreover, 67 compounds from Moroccan aromatic and medicinal plants were tested by molecular docking, of which 11 molecules showed good interaction with the studied enzyme [(Coronavirus (2019$\mathrm{nCoV}$ ) main protease] and three molecules Crocin, Digitoxigenin, b-Eudesmol had shown better interaction Coronavirus (2019-nCoV) main protease) (Aanouz et al., 2021). Crocin, a compound from Crocus Sativus, inhibited the replication of HSV (Soleymani et al., 2018). Digitoxigenin is a compound from Nerium oleander and studied for its antiviral and anticancer activity (Boff et al., 2019). B-Eudesmol was extracted from Lauris nobilis has significant antiviral activity (Astani et al., 2011).

\section{Medicinal Plants for Ebola Virus}

Medicinal plants target viruses through various mechanisms. Garcinia kola's A 13 components showed activity against Ebola virus probably by binding with membrane proteins, metalloproteases, and Ser/Thr Kinase through the three most featured targets; cannabinoid receptors, cyclin-dependent kinases, and matrix metalloproteinase. The components could also target cathepsin, collagenase, and another matrix metalloproteinase (King, 2000; Homsy et al., 2004; David et al., 2017). Baicalin from (Scutellariae Radix), a natural product from the plant, acts on chemokine receptors and inhibits the entry of HIV (Kitamura et al., 1998; Li et al., 2000; Wang et al., 2004). The N-butanol fraction of Bredelia micrantha showed reverse transcriptase inhibition activity. Terpenes showed an inhibitory effect against the protease enzyme (Hussein et al., 1999; Huang and Chen, 2002; Tolo et al., 2006; Yu et al., 2006).

\section{Medicinal Plants for HIV}

There are different targets for HIV drug developments. One is the viral envelope which plays a major role in infecting a cell by interacting with CD4 and chemokine receptors CCR5 and CXCR4. CV-N and Baicalin is a natural product from a plant source that acts on chemokine receptors and inhibits the entry of HIV (Kitamura et al., 1998; Li et al., 2000; Wang et al., 2004). The reverse transcriptase enzyme is also a target for drug development. The study comparing organic solvent and an aqueous fraction of various medicinal plants, and the $n$-butanol fraction of Bredelia micrantha showed anti-reverse transcriptase activities. Phytochemicals such as terpenes revealed inhibitory effects against protease enzyme; an important enzyme for proteolytic processing of polyprotein precursor into essential proteins for the assembly of virus particles (Hussein et al., 1999; Huang and Chen, 2002; Yu et al., 2006).

Croton megalobotrys is a plant species which showed the latent HIV-1 reversal activity. Crude extractas of the plant was comparable with known LRA prostatin which induced HIV-1 in J-lat cells. From the fraction of the crude extract, two novel phorbol esters (Namushal and 2) were identified. The previous study also showed that multiple phorbol esters had anti-HIV-1 activities (El-Mekkawy et al., 2000) and function as LRAs (Tietjen et al., 2018).

\section{Medicinal Plants for Hepatitis Virus}

Medicinal plants have been widely used to treat the hepatitis virus. Out of five plants examined for anti-Hepatitis B virus, three exhibited anti-hepatitis B in vitro with a CC50 value of more than $100 \mu \mathrm{g} / \mathrm{ml}$. These were aqueous extracts from Carissa edulis (Apocynaceae), Prunus africana Kalkman (Rosaceae) and the methanol extract from Acacia mellifera Benth (Fabaceae). Extracts of $C$. edulis exhibited the highest activity; an over $12.15 \%$ inhibition rate relative to the negative control. $P$. africana and $A$. mellifera extract demonstrated 5\% inhibition and $2.15 \%$ inhibition respectively, relative to controls. Further confirmation of the activity of these plants using the quantitative real-time PCR technique showed the aqueous extract of $C$. edulis and the methanol extract of $A$. mellifera exhibited sustained activity over a range of plant extract concentrations from $31.25 \mu \mathrm{g} / \mathrm{ml}$ to $125 \mu \mathrm{g} / \mathrm{ml}$. The evaluation of the $\mathrm{EC}_{50}$ the two plant extracts exhibiting notable anti-HBV activity using this technique yielded; $C$. edulis' EC $_{50}$ was $331.6 \mu \mathrm{g} / \mathrm{ml}$ while that of $A$. mellifera was $295.0 \mu \mathrm{g} / \mathrm{ml}$ (Kwena, 2014).

\section{African Medicinal Plants for Influenza Virus} Influenza virus infection remains a major health problem for animals and humans. Medicinal plants are becoming increasingly popular and included in primary health care in different parts of the world. A study conducted on methanol, ethanol, acetone, hot and cold aqueous extract of five plants (Pittosporum viridiflorum, Cussonia spicata, Rapanea melanophloeos, Tabernaemontana ventricosa, Clerodendrum glabrum) against influenza A virus exhibited antiviral effect. Most effective result were obtained from Rapanea melanophloeos methanol leaf extract $\left(\mathrm{EC}_{50}=\right.$ $113.3 \mu \mathrm{g} / \mathrm{ml}$ ) and Pittosporum viridiflorum methanol, 100 and $30 \%$ ethanol and acetone leaf extracts $\left(\mathrm{EC}_{50}\right.$ values $=3.6,3.4,19.2$, $82.3 \mu \mathrm{g} / \mathrm{ml}$, respectively) (Mehrbod et al., 2018). Ethiopian medicinal plants like Acokanthera schimperi, Euclea schimperi, leaf extracts of Inula confertiflora prevent influenza A virus replication and those of Melilotus elegans were active against influenza A virus (Gebre-Mariam et al., 2006) (Table 2).

\section{Medicinal Plants for Herpes Simplex Virus}

In sub-Saharan Africa, high prevalence rates between 60 and $80 \%$ in young adults have been recorded in population-based studies. It is usually managed by antiviral drugs such as a nucleoside analog acyclovir. However, resistance to ACV has been reported mainly among immunocompromised patients (Morfin and 
Thouvenot, 2003). Medicinal plants have been considered as an alternative for the development of a new drug to overcome the resistance to the modern drug. The study was conducted on an aqueous extract from the root bark of Carissa edulis (Apocynaceae) has shown significant anti-HSV activity in vitro and in vivo (Omino and Kokwaro, 1993). The extract significantly inhibited the formation of plaques in Vero E6 cells infected with $100 \mathrm{PFU}$ of the wild-type strains of HSV by $100 \%$ at $50 \mu \mathrm{g} / \mathrm{ml}$ in vitro with minimal cell cytotoxicity (Tolo et al., 2006). The extracts from four plants; Lannea schweinfurthii, Combretum adenogonium, Ficus sycomorus, and Terminalia mollis showed strong antiviral activity against Herpes Simplex Virus type 1. Out of 42 Egyptian medicinal plants, Ephedra alata and Moringa peregrina are found to have antiviral activity against HSV. Also, the results revealed that Capparis sinaica, Tamarix nilotica, and Cyperus rotundus are found to have a virucidal effect against HSV(Soltan and Zaki, 2009).

The current study is only a preliminary study where some studies reported naively. As all studies in vitro possible dose range, duration of action and in vivo pharmacodynamics properties cannot be established.

In conclusion, African medicinal plants pose significant antiviral activities and could potentially be candidates for viral disease treatment and/or management. It is imperative therefore that research on currently available African medicinal plants be highly recommended. Outcomes from such studies would

\section{REFERENCES}

Aanouz, I., Belhassan, A., El-Khatabi, K., Lakhlifi, T., El-Ldrissi, M., and Bouachrine, M. (2021). Moroccan Medicinal Plants as Inhibitors against SARS-CoV-2 Main Protease: Computational Investigations. J. Biomol. Struct. Dyn. 39 (8), 2971-2979. doi:10.1080/07391102.2020.1758790

Abera, B. (2014). Medicinal Plants Used in Traditional Medicine by Oromo People, Ghimbi District, Southwest Ethiopia. J. Ethnobiol. Ethnomed 10, 40. doi:10.1186/1746-4269-10-40

Amenu, E. (2007). Use and Management of Medicinal Plants by Indigenous People of Ejaji Area (Chelya Woreda) West Shoa, Ethiopia: An Ethnobotanical Approach. Addis Ababa, Ethiopia: Addis Ababa University.

Anani, K., Hudson, J. B., de Souza, C., Akpagana, K., Tower, G. H., Arnason, J. T., et al. (2000). Investigation of Medicinal Plants of Togo for Antiviral and Antimicrobial Activities. Pharm. Biol. 38 (1), 40-45. doi:10.1076/13880209(200001)3811-BFT040

Ang, L., Song, E., Lee, H. W., and Lee, M. S. (2020). Herbal Medicine for the Treatment of Coronavirus Disease 2019 (COVID-19): A Systematic Review and Meta-Analysis of Randomized Controlled Trials. J. Clin. Med. 9 (5), 1583. doi:10.3390/jcm9051583

Astani, A., Reichling, J., and Schnitzler, P. (2011). Screening for Antiviral Activities of Isolated Compounds from Essential Oils. Evid. Based Complement. Alternat Med. 2011, 253643. doi:10.1093/ecam/nep187

Attah, A. F., Fagbemi, A. A., Olubiyi, O., Dada-Adegbola, H., Oluwadotun, A., Elujoba, A., et al. (2021). Therapeutic Potentials of Antiviral Plants Used in Traditional African Medicine with COVID-19 in Focus: A Nigerian Perspective. Front. Pharmacol. 12, 596855. doi:10.3389/fphar.2021.596855

Bagla, V. P., McGaw, L. J., and Eloff, J. N. (2012). The Antiviral Activity of Six South African Plants Traditionally Used against Infections in Ethnoveterinary Medicine. Vet. Microbiol. 155 (2-4), 198-206. Epub 2011/10/11. doi:10.1016/ j.vetmic.2011.09.015

Bessong, P. O., Obi, C. L., Andréola, M. L., Rojas, L. B., Pouységu, L., Igumbor, E., et al. (2005). Evaluation of Selected South African Medicinal Plants for Inhibitory Properties against Human Immunodeficiency Virus Type 1 potentially lead to breakthrough discoveries for the management and/or treatment of COVID-19 and various other viral infections upon appropriate optimization.

\section{DATA AVAILABILITY STATEMENT}

The original contributions presented in the study are included in the article/Supplementary Material, further inquiries can be directed to the corresponding author.

\section{AUTHOR CONTRIBUTIONS}

PO, AW, and CT conceived the idea. TB, SD, AM, NT, NA, and $\mathrm{BL}$ extracted data and critically reviewed the primary studies. TB and SD analyzed the data and wrote the first draft of the manuscript. All authors reviewed and approved the manuscript.

\section{ACKNOWLEDGMENTS}

The authors would like to acknowledge Ambo University, Mbarara University of Science and Technology, and Hawassa University for their support of this article through providing access to the internet and databases for the review.

Reverse Transcriptase and Integrase. J. Ethnopharmacol. 99 (1), 83-91. doi:10.1016/j.jep.2005.01.056

Beuscher, N., Bodinet, C., Neumann-Haefelin, D., Marston, A., and Hostettmann, K. (1994). Antiviral Activity of African Medicinal Plants. J. Ethnopharmacol. 42 (2), 101-109. doi:10.1016/0378-8741(94)90103-1

Boff, L., Munkert, J., Ottoni, F. M., Zanchett Schneider, N. F., Ramos, G. S., Kreis, W., et al. (2019). Potential Anti-herpes and Cytotoxic Action of Novel Semisynthetic Digitoxigenin-Derivatives. Eur. J. Med. Chem. 167, 546-561. Epub 2019/02/25. doi:10.1016/j.ejmech.2019.01.076

Cambaza, E. M. (2020). The African Miracle: why COVID-19 seems to spread slowly in Sub-Saharan Africa. Revista Científica da UEM: Série Ciências Biomédicas e Saúde Pública. COVID, 1-8. preprint. doi:10.13140/ RG.2.2.23824.02564

Chiang, L. C., Chang, J. S., Chen, C. C., Ng, L. T., and Lin, C. C. (2003). Anti-Herpes Simplex Virus Activity of Bidens Pilosa and Houttuynia Cordata. Am. J. Chin. Med. 31 (03), 355-362. doi:10.1142/S0192415X03001090

Clain, E., Sinigaglia, L., Koishi, A. C., Gorgette, O., Gadea, G., Viranaicken, W., et al. (2018). Extract from Aphloia Theiformis, an Edible Indigenous Plant from Reunion Island, Impairs Zika Virus Attachment to the Host Cell Surface. Sci. Rep. 8, 10856. doi:10.1038/s41598-018-29183-2

Cos, P., Hermans, N., De Bruyne, T., Apers, S., Sindambiwe, J. B., Vanden Berghe, D., et al. (2002). Further Evaluation of Rwandan Medicinal Plant Extracts for Their Antimicrobial and Antiviral Activities. J. Ethnopharmacol 79 (2), 155-163. doi:10.1016/s0378-8741(01)00362-2

Cos, P., Hermans, N., De, B. T., Apers, S., Sindambiwe, J. B., Witvrouw, M., et al. (2002). Antiviral Activity of Rwandan Medicinal Plants against Human Immunodeficiency Virus Type-1 (HIV-1). Phytomedicine 9 (1), 62-68. doi:10.1078/0944-7113-00083

David, S., Toluwase, F., and Oluwasegun, O. (2017). Bioinformatics Analysis of Garcinia Kola Active Components and Glycoproteins of Ebola Virus (Zaire Ebolavirus). J. Chem. Pharm. 9 (4), 364-370.

Duraipandiyan, V., and Ignacimuthu, S. (2009). Antibacterial and Antifungal Activity of Flindersine Isolated from the Traditional Medicinal Plant, Toddalia Asiatica (L.) Lam. J. Ethnopharmacol. 123 (3), 494-498. doi:10.1016/j.jep.2009.02.020 
El-Mekkawy, S., Meselhy, M. R., Nakamura, N., Hattori, M., Kawahata, T., and Otake, T. (2000). Anti-HIV-1 Phorbol Esters from the Seeds of Croton Tiglium. Phytochemistry 53 (4), 457-464. doi:10.1016/s0031-9422(99) 00556-7

Fan, A. Y., Gu, S., and Alemi, S. F. (2020). Chinese Herbal Medicine for COVID-19: Current Evidence with Systematic Review and Meta-Analysis. J. Integr. Med. 18 (5), 385-394. doi:10.1016/j.joim.2020.07.008

Fennell, C. W., Lindsey, K. L., McGaw, L. J., Sparg, S. G., Stafford, G. I., Elgorashi, E. E., et al. (2004). Assessing African Medicinal Plants for Efficacy and Safety: Pharmacological Screening and Toxicology. J. Ethnopharmacol 94 (2-3), 205-217. doi:10.1016/j.jep.2004.05.012

Ferrea, G., Canessa, A., Sampietro, F., Cruciani, M., Romussi, G., and Bassetti, D. (1993). In Vitro activity of a Combretum Micranthum Extract against Herpes Simplex Virus Types 1 and 2. Antivir. Res 21 (4), 317-325. doi:10.1016/01663542(93)90010-g

Gebre-Mariam, T., Neubert, R., Schmidt, P. C., Wutzler, P., and Schmidtke, M. (2006). Antiviral Activities of Some Ethiopian Medicinal Plants Used for the Treatment of Dermatological Disorders. J. Ethnopharmacol. 104 (1-2), 182-187. doi:10.1016/j.jep.2005.08.071

Gyebi, G. A., Ogunro, O. B., Adegunloye, A. P., Ogunyemi, O. M., and Afolabi, S. O. (2021). Potential Inhibitors of Coronavirus 3-chymotrypsin-like Protease (3CLpro): an In Silico Screening of Alkaloids and Terpenoids from African Medicinal Plants. J. Biomol. Struct. Dyn. 39 (9), 1-13. doi:10.1080/ 07391102.2020 .1764868

Gyuris, A., Szlávik, L., Minárovits, J., Vasas, A., Molnár, J., and Hohmann, J. (2009). Antiviral Activities of Extracts of Euphorbia Hirta L. Against HIV-1, HIV-2 and SIVmac251. In Vivo 23 (3), 429-432.

Homsy, J., King, R., Balaba, D., and Kabatesi, D. (2004). Traditional Health Practitioners Are Key to Scaling up Comprehensive Care for HIV/AIDS in Sub-saharan Africa. Aids 18 (12), 1723-1725. doi:10.1097/ 01.aids. 0000131380.30479 .16

Huang, L., and Chen, C. H. (2002). Molecular Targets of Anti-HIV-1 Triterpenes. Curr. Drug Targets Infect. Disord. 2 (1), 33-36. doi:10.2174/1568005024605936

Hussein, G., Miyashiro, H., Nakamura, N., Hattori, M., Kawahata, T., Otake, T., et al. (1999). Inhibitory Effects of Sudanese Plant Extracts on HIV-1 Replication and HIV-1 Protease. Phytother Res. 13 (1), 31-36. doi:10.1002/(SICI)10991573(199902)13:1<31::AID-PTR381>3.0.CO;2-C

Kambizi, L., Goosen, B., Taylor, M., and Afolayan, A. (2007). Anti-viral Effects of Aqueous Extracts of Aloe Ferox and Withania Somnifera on Herpes Simplex Virus Type 1 in Cell Culture. S. Afr. J. Sci. 103 (9-10), 359-360.

King, R. (2000). Collaboration with Traditional Healers in HIV/AIDS Prevention and Care in Sub-saharan Africa: A Literature Review. Geneva: UNAIDS.

Kitamura, K., Honda, M., Yoshizaki, H., Yamamoto, S., Nakane, H., Fukushima, M., et al. (1998). Baicalin, an Inhibitor of HIV-1 Production In Vitro. Antivir. Res 37 (2), 131-140. doi:10.1016/s0166-3542(97)00069-7

Kudi, A. C., and Myint, S. H. (1999). Antiviral Activity of Some Nigerian Medicinal Plant Extracts. J. Ethnopharmacol. 68 (1-3), 289-294. doi:10.1016/s03788741(99)00049-5

Kwena, M. H. (2014). Anti-viral Activities of Selected Kenyan Medicinal Plants against the Hepatitis-B Virus. Nairobi: University of Nairobi.

Li, B. Q., Fu, T., Gong, W. H., Dunlop, N., Kung, H., Yan, Y., et al. (2000). The Flavonoid Baicalin Exhibits Anti-inflammatory Activity by Binding to Chemokines. Immunopharmacology 49 (3), 295-306. doi:10.1016/s01623109(00)00244-7

Liberati, A., Altman, D. G., Tetzlaff, J., Mulrow, C., Gøtzsche, P. C., Ioannidis, J. P., et al. (2009). The PRISMA Statement for Reporting Systematic Reviews and Meta-Analyses of Studies that Evaluate Health Care Interventions: Explanation and Elaboration. Plos Med. 6 (10), e1000100-e34. doi:10.7326/0003-4819-1514-200908180-0013610.1371/journal.pmed.1000100

Liu, M., Gao, Y., Yuan, Y., Yang, K., Shi, S., Zhang, J., et al. (2020). Efficacy and Safety of Integrated Traditional Chinese and Western Medicine for Corona Virus Disease 2019 (COVID-19): a Systematic Review and MetaAnalysis. Pharmacol. Res. 158 (2020), 104896. doi:10.1016/ j.phrs.2020.104896

Liu, X., Zhang, M., He, L., and Li, Y. (2006). Chinese Herbs Combined with Western Medicine for Severe Acute Respiratory Syndrome (SARS). Cochrane Database Syst. Rev. 10, CD004882, 2006 . Published 2006 Jan 25. doi:10.1002/ 14651858.CD004882.pub3
Lu, S. Y., Qiao, Y. J., Xiao, P. G., and Tan, X. H. (2005). Identification of Antiviral Activity of Toddalia Asiatica against Influenza Type A Virus. Zhongguo Zhong Yao Za Zhi 30 (13), 998-1001.

Maregesi, S. M., Pieters, L., Ngassapa, O. D., Apers, S., Vingerhoets, R., Cos, P., et al. (2008). Screening of Some Tanzanian Medicinal Plants from Bunda District for Antibacterial, Antifungal and Antiviral Activities. J. Ethnopharmacol. 119 (1), 58-66. doi:10.1016/j.jep.2008.05.033

Mehrbod, P., Abdalla, M. A., Njoya, E. M., Ahmed, A. S., Fotouhi, F., Farahmand, B., et al. (2018). South African Medicinal Plant Extracts Active against Influenza A Virus. BMC Complement. Altern. Med. 18 (1), 112. doi:10.1186/s12906-0182184-y

More, G. K., Makola, R. T., and Prinsloo, G. (2021). In Vitro Evaluation of Anti-rift Valley Fever Virus, Antioxidant and Anti-inflammatory Activity of South African Medicinal Plant Extracts. Viruses 13 (2), 221. doi:10.3390/v13020221

Morfin, F., and Thouvenot, D. (2003). Herpes Simplex Virus Resistance to Antiviral Drugs. J. Clin. Virol. 26 (1), 29-37. doi:10.1016/s1386-6532(02) 00263-9

Muhammad, F. (2020). COVID-19 Pandemic: The Role of Traditional Medicine. Int. J. Infect. 7 (3), e107090. doi:10.5812/iji.107090

Nakano, M., Itoh, Y., Mizuno, T., and Nakashima, H. (1997). Polysaccharide from Aspalathus Linearis with strong Anti-HIV Activity. Biosci. Biotechnol. Biochem. 61 (2), 267-271. doi:10.1271/bbb.61.267

Nasr-Eldin, M., Abdelhamid, A., and Baraka, D. (2018). Antibiofilm and Antiviral Potential of Leaf Extracts from Moringa Oleifera and Rosemary (Rosmarinus Officinalis Lam.). Egypt. J. Microbiol. 52 (1), 129-139. doi:10.21608/ ejm.2017.1439.1027

Ndhlala, A. R., Amoo, S. O., Ncube, B., Moyo, M., Nair, J. J., and Van Staden, J. (2013). Antibacterial, Antifungal, and Antiviral Activities of African Medicinal Plants. Med. Plant Res. Africa 2013, 621-659. Elsevier. doi:10.1016/b978-0-12405927-6.00016-3

Nwodo, U. U., Ngene, A. A., Iroegbu, C. U., Onyedikachi, O. A., Chigor, V. N., and Okoh, A. I. (2011). In Vivo evaluation of the Antiviral Activity of Cajanus Cajan on Measles Virus. Arch. Virol. 156 (9), 1551-1557. doi:10.1007/s00705-0111032-x

Ogbole, O. O., Adeniji, J. A., Ajaiyeoba, E., and Adu, D. F. (2013). Anti-polio Virus Activity of Medicinal Plants Selected from the Nigerian Ethno-Medicine. Afr. J. Biotechno 12 (24), 3878-3883. doi:10.5897/AJB12.2730

Ogbole, O. O., Akinleye, T. E., Segun, P. A., Faleye, T. C., and Adeniji, A. J. (2018). In Vitro antiviral Activity of Twenty-Seven Medicinal Plant Extracts from Southwest Nigeria against Three Serotypes of Echoviruses. Virol. J. 15 (1), 110. doi:10.1186/s12985-018-1022-7

Ojo, O., Oluyege, J., and Famurewa, O. (2009). Antiviral Properties of Two Nigerian Plants. Afr. J. Plant Sci. 3 (7), 157-159. doi:10.5897/AJPS.9000025

Omino, E. A., and Kokwaro, J. O. (1993). Ethnobotany of Apocynaceae Species in Kenya. J. Ethnopharmacol. 40 (3), 167-180. doi:10.1016/0378-8741(93)90065-d

Rahmasaria, R., Haruyama, T., Charyasriwong, S., Nishida, T., and Kobayashi, N. (2017). Antiviral Activity of Aspalathus Linearis against Human Influenza Virus. Nat. Prod. Commun. 12 (4), 599-602. doi:10.1177/1934578x1701200432

Selvarani, V. (2009). Multiple Inflammatory and Antiviral Activities in Adansonia Digitata (Baobab) Leaves, Fruits and Seeds. J. Med. Plant Res. 3 (8), 576-582. doi:10.5897/JMPR.9000918

Serkedjieva, J. (2003). Influenza Virus Variants with Reduced Susceptibility to Inhibition by a Polyphenol Extract from Geranium Sanguineum L. Pharmazie 58 (1), 53-57. Epub 2003/03/08.

Shahrajabian, M. H., Sun, W., Shen, H., and Cheng, Q. (2020). Chinese Herbal Medicine for SARS and SARS-CoV-2 Treatment and Prevention, Encouraging Using Herbal Medicine for COVID-19 Outbreak. Acta Agriculturae Scand. Section B - Soil Plant Sci. 70 (5), 437-443. doi:10.1080/09064710.2020.1763448

Sindambiwe, J. B., Calomme, M., Cos, P., Totté, J., Pieters, L., Vlietinck, A., et al. (1999). Screening of Seven Selected Rwandan Medicinal Plants for Antimicrobial and Antiviral Activities. J. Ethnopharmacol. 65 (1), 71-77. doi:10.1016/s0378-8741(98)00154-8

Soleymani, S., Zabihollahi, R., Shahbazi, S., and Bolhassani, A. (2018). Antiviral Effects of Saffron and its Major Ingredients. Curr. Drug Deliv. 15 (5), 698-704. Epub 2017/12/01. doi:10.2174/1567201814666171129210654

Soltan, M. M., and Zaki, A. K. (2009). Antiviral Screening of Forty-Two Egyptian Medicinal Plants. J. Ethnopharmacol. 126 (1), 102-107. doi:10.1016/ j.jep.2009.08.001 
Sultana, N. (2011). Clinically Useful Anticancer, Antitumor, and Antiwrinkle Agent, Ursolic Acid and Related Derivatives as Medicinally Important Natural Product. J. Enzyme Inhib. Med. Chem. 26 (5), 616-642. doi:10.3109/ 14756366.2010.546793

Sunday, O. A., Munir, A. B., Akeeb, O. O., Bolanle, A. A., and Badaru, S. (2010). Antiviral Effect of Hibiscus sabdariffa and Celosia Argentea on Measles Virus. Afr. J. Microbiol. Res. 4 (4), 293-296. doi:10.5897/ AJMR.9000096

Tietjen, I., Gatonye, T., Ngwenya, B. N., Namushe, A., Simonambanga, S., Muzila, M., et al. (2016). Croton Megalobotrys Müll Arg. And Vitex Doniana (Sweet): Traditional Medicinal Plants in a Three-step Treatment Regimen that Inhibit In Vitro Replication of HIV-1. J. Ethnopharmacol. 191, 331-340. doi:10.1016/ j.jep.2016.06.040

Tietjen, I., Ngwenya, B. N., Fotso, G., Williams, D. E., Simonambango, S., Ngadjui, B. T., et al. (2018). The Croton Megalobotrys Müll Arg. Traditional Medicine in HIV/AIDS Management: Documentation of Patient Use, In Vitro Activation of Latent HIV-1 Provirus, and Isolation of Active Phorbol Esters. J. Ethnopharmacol. 211, 267-277. doi:10.1016/j.jep.2017.09.038

Tih, F. (2020). WHO Holds Meeting with African Traditional Medicine Experts. Ankara, Turkey: Anadolu Agency.

Tolo, F. M., Rukunga, G. M., Muli, F. W., Njagi, E. N., Njue, W., Kumon, K., et al. (2006). Anti-viral Activity of the Extracts of a Kenyan Medicinal Plant Carissa Edulis against Herpes Simplex Virus. J. Ethnopharmacol. 104 (1-2), 92-99. doi:10.1016/j.jep.2005.08.053

Tolo, F. M., Rukunga, G. M., Muli, F. W., Ochora, J., Eizuru, Y., Muthaura, C. N., et al. (2007). In Vitro anti-viral Activity of Aqueous Extracts of Kenyan Carissa Edulis, Prunus Africana and Melia Azedarach against Human Cytomegalovirus. Afr. J. Med. Health Sci. 14 (3), 143-148.

Traore, T. K., Andre, T., Noufou, O., Ernest, S. N., Yhi-pene, N. d. J., and Pierre, G. I. (2018). Ethnopharmacological Plants Used to Treat Hepatitis and Their Antioxidant Activity of District of Bobo-Dioulasso (Burkina Faso). Int. J. Pharmc Res. 8 (3), 15-23. doi:10.7439/ijpr.v8i3.4643

Trilla, A., Trilla, G., and Daer, C. (2008). The 1918 "Spanish Flu" in Spain. Clin. Infect. Dis. 47 (5), 668-673. doi:10.1086/590567

Vlietinck, A. J., Van Hoof, L., Totté, J., Lasure, A., Vanden Berghe, D., Rwangabo, P. C., et al. (1995). Screening of Hundred Rwandese Medicinal Plants for Antimicrobial and Antiviral Properties. J. Ethnopharmacol 46 (1), 31-47. doi:10.1016/0378-8741(95)01226-4

Wang, Q., Wang, Y. T., Pu, S. P., and Zheng, Y. T. (2004). Zinc Coupling Potentiates Anti-HIV-1 Activity of Baicalin. Biochem. Biophys. Res. Commun. 324 (2), 605-610. doi:10.1016/j.bbrc.2004.09.093

World Health Assembly (2003). “Traditional Medicine: Report by the Secretariat,". Fifty-sixth world health assembly, Provisional agenda item 14.10 (Geneva, Switzerland: World Health Organization). Available at: https://apps.who.int/ iris/handle/10665/78244.
World Health Organization (2003). Cumulative Number of Reported Probable Cases of Severe Acute Respiratory Syndrome (SARS). Available at: http://www. who.int/csr/sars/country/2003_04_22/en/.

World Health Organization (2005). National Policy on Traditional Medicine and Regulation of Herbal Medicines: Report of a WHO Global Survey. Available at: https://apps.who.int/iris/handle/10665/43229.

World Health Organization (2020). Weekly Epidemiological Update on COVID19 - 3 August 2021. Available at: https://www.who.int/publications/m/item/ weekly-epidemiological-update-on-covid-19-3-august-2021.

Xiong, X., Wang, P., Su, K., Cho, W. C., and Xing, Y. (2020). Chinese Herbal Medicine for Coronavirus Disease 2019: a Systematic Review and MetaAnalysis. Pharmacol. Res. 160 (2020), 105056. doi:10.1016/j.phrs.2020.105056

Yoosook, C., Bunyapraphatsara, N., Boonyakiat, Y., and Kantasuk, C. (2000). Antiherpes Simplex Virus Activities of Crude Water Extracts of Thai Medicinal Plants. Phytomedicine 6 (6), 411-419. doi:10.1016/S0944-7113(00)80068-9

Yu, D., Sakurai, Y., Chen, C. H., Chang, F. R., Huang, L., Kashiwada, Y., et al. (2006). Anti-AIDS Agents 69. Moronic Acid and Other Triterpene Derivatives as Novel Potent Anti-HIV Agents. J. Med. Chem. 49 (18), 5462-5469. doi:10.1021/jm0601912

Zhang, D. H., Wu, K. L., Zhang, X., Deng, S. Q., and Peng, B. (2020). In Silico screening of Chinese Herbal Medicines with the Potential to Directly Inhibit 2019 Novel Coronavirus. J. Integr. Med. 18 (2), 152-158. doi:10.1016/j.joim.2020.02.005

Zhang, M. M., Liu, X. M., and He, L. (2004). Effect of Integrated Traditional Chinese and Western Medicine on SARS: a Review of Clinical Evidence. World J. Gastroenterol. 10 (23), 3500-3505. doi:10.3748/wjg.v10.i23.3500

Zumla, A., Hui, D. S., and Perlman, S. (2015). Middle East Respiratory Syndrome. Lancet 386 (9997), 995-1007. doi:10.1016/S0140-6736(15)60454-8

Conflict of Interest: The authors declare that the research was conducted in the absence of any commercial or financial relationships that could be construed as a potential conflict of interest.

Publisher's Note: All claims expressed in this article are solely those of the authors and do not necessarily represent those of their affiliated organizations, or those of the publisher, the editors and the reviewers. Any product that may be evaluated in this article, or claim that may be made by its manufacturer, is not guaranteed or endorsed by the publisher.

Copyright (C) 2021 Beressa, Deyno, Mtewa, Aidah, Tuyiringire, Lukubye, Weisheit, Tolo and Ogwang. This is an open-access article distributed under the terms of the Creative Commons Attribution License (CC BY). The use, distribution or reproduction in other forums is permitted, provided the original author(s) and the copyright owner(s) are credited and that the original publication in this journal is cited, in accordance with accepted academic practice. No use, distribution or reproduction is permitted which does not comply with these terms. 